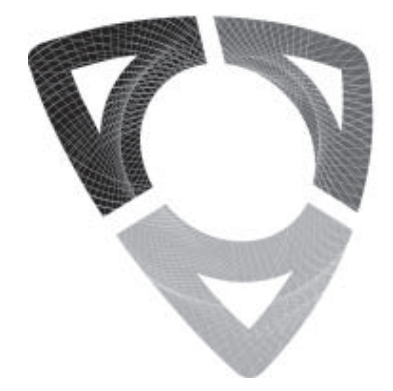

\title{
American Accounting Association
}

\section{Thought Leaders in Accounting}

The Accounting Review • Issues in Accounting Education • Accounting Horizons Accounting Historians Journal - Accounting and the Public Interest - Auditing: A Journal of Practice \& Theory Behavioral Research in Accounting • Current Issues in Auditing $\cdot$ Journal of Emerging Technologies in Accounting $\cdot$ Journal of Financial Reporting • Journal of Forensic Accounting Research • Journal of Governmental \& Nonprofit Accounting • Journal of Information Systems · Journal of International Accounting Research - Journal of Management Accounting Research - The ATA Journal of Legal Tax Research - The Journal of the American Taxation Association

\section{Online Early - Preprint of Accepted Manuscript}

This is a PDF file of a manuscript that has been accepted for publication in an American Accounting Association journal. It is the final version that was uploaded and approved by the author(s). While the paper has been through the usual rigorous peer review process for AAA journals, it has not been copyedited, nor have the graphics and tables been modified for final publication. Also note that the paper may refer to online Appendices and/or Supplements that are not yet available. The manuscript will undergo copyediting, typesetting and review of page proofs before it is published in its final form, therefore the published version will look different from this version and may also have some differences in content.

We have posted this preliminary version of the manuscript as a service to our members and subscribers in the interest of making the information available for distribution and citation as quickly as possible following acceptance.

The DOI for this manuscript and the correct format for citing the paper are given at the top of the online (html) abstract.

Once the final published version of this paper is posted online, it will replace this preliminary version at the specified DOI. 


\title{
How do Risk-Based Inspections Impact Auditor Behavior? Experimental Evidence on the PCAOB's Process
}

\author{
Lori Shefchik Bhaskar \\ Indiana University \\ lbhaskar@indiana.edu
}
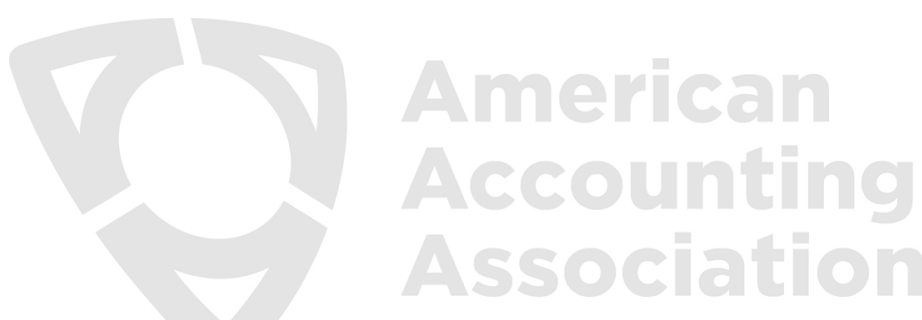

Running Head: How do Risk-Based Inspections Impact Auditor Behavior?

Editor's note: Accepted by Mark E. Peecher, under the Senior Editorship of Mark L. DeFond Submitted January 2016

Accepted December 2019

Acknowledgments: This paper is based on my dissertation work completed at the Georgia Institute of Technology. I am deeply grateful to my dissertation chair, Bryan Church, for his guidance and mentorship, and to my other committee members, Jeffrey Hales, Kathryn Kadous, Arnold Schneider, and Adam Vitalis for their invaluable feedback. I am also thankful for helpful comments and suggestions received from Mark Peecher (Editor), two anonymous reviewers, E.B. Altiero, Ashley Austin, Timothy Bauer, Sudhir Bhaskar, Melissa Carlisle, James Cox, Cassandra Estep, Brent Garza, Joseph Johnson, Bill Kinney, Jason Kuang, Yuebing (Sarah) Liu, Tracie Majors, Paul Micas, Kara Obermire, Kristina Rennekamp, Marcy Shepardson, Geoff Sprinkle, Matthew Stern, Shankar Venkataraman, Helen Xu, and seminar participants at Arizona State University, Chapman University, Cornell University, Georgia State University, Indiana University, University of Arizona, University of Illinois at UrbanaChampaign, University of Massachusetts Amherst, University of Wisconsin-Madison, the 2014 Deloitte Foundation/ University of Kansas Auditing Symposium, and the 2012 AAA Annual Meeting.

Supplemental material can be accessed by clicking the link in Appendix A. 


\title{
How do Risk-Based Inspections Impact Auditor Behavior? Experimental Evidence on the PCAOB's Process
}

\begin{abstract}
I provide theory-based causal evidence on the effects of risk-based regulatory inspections, modeled after the PCAOB's, on auditor behavior in a multi-client setting where clients with relatively higher misstatement risk ("higher-risk" clients) have a higher risk of being inspected than clients with relatively lower misstatement risk ("lower-risk" clients). I predict and find inspections increase auditor effort, but only for higher-risk clients. Inspections impair auditors' decision performance for lower-risk clients relative to a regime without inspections and relative to higher-risk clients within an inspections regime, ceteris paribus. Theory-based process model results show inspections increase auditors' perceived inspection risks, which increase auditor effort for higher-risk clients, but also increase auditors' task-related anxiety resulting in decreased decision performance for lower-risk clients. Notwithstanding the previously-identified benefits, this study identifies potential unintended consequences of riskbased regulatory inspections.
\end{abstract}

Keywords: auditor behavior; audit regulation; audit quality; client risk; PCAOB inspections 


\section{INTRODUCTION}

The U.S. Public Company Accounting Oversight Board (PCAOB) and audit regulators across the globe conduct periodic risk-based inspections of audits to assess compliance with applicable auditing standards to promote audit quality (PCAOB 2019; IFIAR 2019). ${ }^{1}$ Both regulators and academics call for research on how these inspections affect auditor behavior. ${ }^{2}$ While prior research generally finds positive associations between regulatory inspections and audit quality (see Knechel et al. 2013 for a review), research to date has not examined whether the effects of inspections differ for clients with varying levels of client risk. This issue is important in part because resource-constrained auditors anticipating risk-based regulatory inspections likely manage their inspection risks by focusing more on clients with relatively higher misstatement risks ("higher-risk" clients), and therefore a higher likelihood of being selected for inspection, and less on other clients. ${ }^{3}$ Thus, notwithstanding the benefits for higherrisk clients, I provide theory and evidence as to why risk-based regulatory inspections likely have unintended effects on clients with relatively lower misstatement risks ("lower-risk" clients), and therefore a lower likelihood of being selected for inspection.

While research to date has not examined potential unintended consequences of regulatory inspections on auditor behavior for lower-risk clients, researchers and audit regulators have

\footnotetext{
${ }^{1}$ Additional audit regulators with risk-based inspections of audits include the Canadian Public Accountability Board (CPAB), the Financial Reporting Council (FRC) in the UK, the Australian Securities and Investments Commission (ASIC), and most of the other members in the International Forum of Independent Audit Regulators (IFIAR).

${ }^{2}$ See, e.g., Bedard et al. (2008, 208); Daugherty and Tervo (2010, 190); DeFond (2010, 104); Church and Shefchik (2012, 62); Houston and Stefaniak (2013, 25); PCAOB (2013); Knechel et al. (2013, 405); and Peecher, Solomon, and Trotman (2013).

${ }^{3}$ Most audit regulators predominantly select audits for inspection using a risk-based approach (IFIAR 2019). For example, the PCAOB chooses audits evaluated to have a higher risk of material misstatement based on client-related factors (e.g., issuer size and industry) and auditor-related factors (e.g., audit partner and inspection history) (PCAOB 2008, 2016a). Due to the multi-faceted nature of misstatement risk, "higher-" and "lower-risk" clients do not necessarily reflect large and small client size. For example, some large clients have a relatively low risk of material misstatement and within an auditor's portfolio of large clients, some have relatively higher and lower misstatement risks. Also, assessing misstatement risk is subjective and complex, which likely leads to differences in the regulators' and auditors' assessments. Nonetheless, Houston and Stefaniak (2013) find that a majority of U.S. audit partners try to predict, ex ante, which engagements will be selected for PCAOB inspection.
} 
expressed concerns about how auditors manage inspection risks (Glover and Prawitt 2013;

Glover, Taylor, and Wu 2014; PCAOB 2013; Houston and Stefaniak 2013). As former PCAOB

Board member Franzel (2013) notes:

I would be concerned if a partner is making decisions about staffing levels and hours based on that partner's assessment of whether or not that audit will be inspected. I would hope the same levels of quality and expertise would be applied to an audit regardless ... that makes me question what's happening on the audits that partners think are not being inspected?

The concern is that while regulatory inspections improve average audit quality, they likely have disproportionate benefits for relatively higher-risk clients and unintended costs for relatively lower-risk clients.

In my study, I use an experimental-economics approach to examine the causal effects of risk-based regulatory inspections on auditor effort and decision performance quality in a multiclient setting. ${ }^{4}$ In a $2 \times 2$ mixed-design experiment, I manipulate inspections betweenparticipants (present or absent) and client risk within-participants (relatively higher and lower by varying the level of misstatement risk). Participants make audit effort and reporting decisions for the two clients over 20 periods. I model the inspections process after the PCAOB's. In the inspections condition, there is a chance that participants' work will be inspection, and if inspected, clients with a higher misstatement risk have a higher chance of being selected for inspection relative to others in the participants' portfolios. Participants incur economic and social penalties for insufficient audit effort identified during inspections. Participants accumulate

\footnotetext{
${ }^{4}$ Following prior research in auditing (e.g., Bowlin, Hobson, Piercy 2015; Kachelmeier, Majors and Williamson 2014), I test my psychology-based predictions in a laboratory experiment that follows the principles of experimental economics (Kachelmeier and King 2002). This method is ideal for studying auditor behavior in a multi-client, repeated setting that captures the key concepts and incentives in natural auditing environments. The experimental approach maximizes internal validity as it controls for confounding factors that naturally occur in audit environments (Libby, Bloomfield, and Nelson 2002). By using a controlled setting with incentives that parallel those in the auditing practice, I am able to generalize my theory to real-world auditors. As with all experiments, the setting includes assumptions and does not incorporate all aspects of auditing environments. Future research could examine whether using different assumptions and/or incorporating other aspects from audit environments would interact with theory employed in this study to affect my results.
} 
earnings based on their decisions and the incentives emulate those in the audit environment. Specifically, audit effort resources are limited, effort is costly, and higher effort yields a greater signal about the accuracy of the clients' financial statements that contain uncertainty. Participants also face a disincentive of issuing an adverse report on their clients' financial statements, but they face a much greater disincentive for issuing an incorrect clean audit report if it becomes known that the financial statements contain a material misstatement. Importantly, I design my setting such that the wealth-maximizing effort and reporting decisions are held constant across the inspections conditions, enabling a cleaner test of my predicted psychologybased effects of inspections on participants' behavior.

Naturally, regulatory inspections induce inspection risks - the risk that an auditor will suffer harm as a result of inspections (Stefaniak, Houston, and Brandon 2017, 151). For example, U.S. auditors report that PCAOB inspection deficiencies adversely affect their compensation, promotion status, and professional reputation (Houston and Stefaniak 2013). To manage inspection risks, I predict resource-constrained auditors increase effort more for relatively higher-risk clients (i.e., those more likely to be selected for inspection). In addition, following the pressure-arousal-performance framework (Yerkes and Dodson 1908; Ashton 1990), I also expect inspection risks induce task-related anxiety (i.e., worry over adverse consequences), which negatively impacts judgment performance (Stone and Kadous 1997). Specifically, following attentional control theory in a dual-task paradigm (Eysenck et al. 2007), I expect taskrelated anxiety interrupts auditors' decision processing such that it narrows auditors' attention toward salient clients stimulating the anxiety (i.e., relatively higher-risk clients in a risk-based inspections regime) and away from other less-salient clients. Accordingly, I predict risk-based inspections impair auditors' decision performance for lower-risk clients (i.e., clients outside the 
auditors’ attention spotlight), resulting in lower-quality decisions (e.g., suboptimal, more heuristic-based, more high-risk decisions).

As attentional control theory predicts, I find risk-based inspections affect auditor effort and auditors' decision performance quality differently depending on client risk. First, relative to a regime with no inspections, inspections increase auditor effort significantly more for higherrisk clients than for lower-risk clients: Auditor effort only increases for higher-risk clients and not for lower-risk clients. Second, inspections significantly impair auditors’ decision performance for lower-risk clients measured by instances of low-quality decisions. Specifically, auditors' low-quality decisions more frequently occur for lower-risk clients in an inspections regime relative to a regime with no inspections; and, within an inspections regime, auditors’ lowquality decisions more frequently occur for lower-risk clients than for higher-risk clients, ceteris paribus. ${ }^{5}$ All tests of hypotheses were replicated in a similar preliminary study. ${ }^{6}$

Additional analyses provide theory-consistent evidence on the mechanism underlying how inspections affect auditor behavior. Structural equations-based process model results show that risk-based inspections significantly increase auditors’ perceived inspection risks for higherrisk clients, which significantly increase auditor effort for higher-risk clients. At the same time, auditors’ perceived inspection risks for higher-risk clients significantly increase their task-related anxiety, which significantly increases their instances of low-quality decisions. Second, auditors’

\footnotetext{
${ }^{5}$ I measure low-quality decisions as instances of issuing a clean "high" (versus an adverse "low") report after receiving a highly probable, but imperfect, signal that the financial statements contain a material misstatement (a "low-value" signal). The information and expected outcomes of the decision (i.e., reporting high versus low after a low-value signal) are held constant for all participants regardless of their experimental conditions and their previous effort-level decisions (for that client and in total). As discussed in Section III, I use this measure of impaired decision performance because it is consistent with auditors' willingness to give in to client-preferred incentives and, more importantly, because it captures low-quality decisions consistent with theoretical predictions (i.e., suboptimal, more heuristics-based, and more high-risk decisions induced by task-related anxiety).

${ }^{6}$ The experiment in the preliminary study was identical to that in the main study with the exception that the lowvalue signal was 100 percent accurate. See Tables A1 and A2 in the Online Appendix for results of the preliminary study (see Appendix A for the link to the downloadable file).
} 
task-related anxiety significantly increases their use of suboptimal decision strategies for lowerrisk clients (but not for higher-risk clients), which significantly increases auditors' low-quality decisions.

My study makes several contributions regarding how regulatory inspections affect auditor behavior. My study extends the auditing literature examining the effects of regulatory inspections on audit quality by providing theory-based evidence on the potential unintended effects of risk-based inspections on auditor behavior-impaired decision performance for clients with relatively lower inspection risk. Thus, even if risk-based inspections improve audit quality on average, there likely are disproportionate benefits to higher-risk clients and unintended costs to lower-risk clients. Generalizing theory, these unintended effects of risk-based inspections may affect clients with lower perceived misstatement risk in the auditor's portfolio (e.g., regardless of client size) and potentially lead to increased instances of non-compliance with auditing standards - contrary to the goal of regulatory inspections. The results give credence to concerns raised by audit academics and regulators about the potential unintended effects of risk-based, penalty-based regulatory inspections on auditor behavior (e.g., Daugherty and Tervo 2010; Houston and Stefaniak 2013; Peecher, Solomon, and Trotman 2013; Dowling, Knechel, and Moroney 2015; PCAOB 2016b). For example, Board Member Franzel states the following when discussing the potential benefits and drawbacks of its current inspections regime:

Some have speculated that the less risky audits may have lower incidences of audit deficiencies due to less complexity inherent in those audits, while others speculate that audit deficiencies could actually be higher in that group due to less focus and attention being placed on those audits by the firms (PCAOB 2016b). 
My study also provides theory and evidence on the mechanism underlying the effects of risk-based inspections on resource-constrained auditors ${ }^{7}$ —inspection risks induce task-related anxiety which impairs auditors' decision performance for clients outside the spotlight (i.e., lower-risk clients). Understanding this mechanism is important for identifying mitigating remedies. In light of these findings, audit regulators, academics, and practitioners could examine ways to reduce these potential unintended effects of risk-based inspections, while maintaining the important benefits of the regulatory accountability mechanism. For example, future research could examine whether changes to the inspections process (e.g., incorporating reward-based incentives for high-quality audits in addition to penalty-based incentives for low-quality audits as suggested in Peecher et al. [2013]), could reduce unintended effects due to task-related anxiety while maintaining the benefits of inspections. As another example, future research could examine whether incorporating a random component to the selection of inspections, under current implementation in the U.S. (PCAOB 2017), mitigates the unintended effects by reducing auditors' abilities to manage inspection risks. However, based on the results of my study, this change could potentially enhance auditors’ task-related anxiety and impaired decision performance if auditors perceive high inspection risks but feel unable to manage them.

\section{BACKGROUND AND HYPOTHESES DEVELOPMENT}

Audit regulators across the globe, including the PCAOB, started conducting periodic inspections of audits in the early 2000's to assess compliance with applicable auditing standards to promote audit quality and protect the interests of investors and the public (PCAOB 2017,

\footnotetext{
${ }^{7}$ As described in Section IV, results from a similar, supplementary study with relatively lower resource constraints suggest that the unintended effects of risk-based inspections on auditor behavior are likely restricted to settings with relatively high resource constraints which is consistent with my theoretical predictions. See Tables A3 and A4 in the Online Appendix for results of the supplementary study.
} 
2019; IFIAR 2019). ${ }^{8}$ Archival research generally finds positive associations between regulatory inspections and proxies for average audit quality. For example, PCAOB inspections are associated with improved auditor reporting quality (Gramling, Krishnan, and Zhang 2011; Lamoreaux 2017), enhanced financial reporting quality (Krishnan, Krishnan, and Song 2017; Drake, Goldman, and Lusch 2016), improved quality of internal control audits (DeFond and Lennox 2017), and a higher likelihood of low-quality auditors being dismissed or exiting the market (Abbott, Gunny, and Zhang 2013; Daugherty, Dickins, and Tervo 2011; DeFond and Lennox 2011). Experimental evidence of regulatory inspections on auditor behavior is sparse with two studies finding that auditors increase planned audit effort to clients with higher PCAOB inspection risks (Stefaniak et al. 2017; Winn 2019).

I extend prior research by providing theory and causal evidence regarding how the effects of risk-based regulatory inspections differ for clients with varying levels of risk. In doing so, I also provide theory-based evidence on the process underlying these effects (i.e., isolating the roles of perceived inspection risks and task-related anxiety), which is important for identifying mediating mechanisms. While my setting focuses on the PCAOB's inspections, most of the other audit regulators in the IFIAR (consisting of 55 members) employ similar risk-based inspections, including the CPAB in Canada, the FRC in the UK, and the ASIC in Australia (IFIAR 2019).

\section{Background on PCAOB Inspections}

PCAOB inspections are performed annually for all accounting firms with over 100 issuer clients and once every three years for accounting firms with 100 or fewer issuer clients. The inspections process includes detailed examinations and reviews of certain elements of issuer

\footnotetext{
${ }^{8}$ Prior to the creation of external audit regulators, accounting firms were self-regulated. The PCAOB participated in peer reviews conducted once every three years, overseen by the American Institute of Certified Public Accountants (AICPA). Despite empirical evidence that public company audit clients perceive peer review information as credible (Hilary and Lennox 2005), peer reviews have been criticized for being too lenient and for lacking power to enforce sanctions for low-quality work (Fogarty 1996; DeFond 2010).
} 
engagements selected for inspection ("Part I" of the reports) and an overall evaluation of the accounting firms' quality controls ("Part II" of the reports). The PCAOB inspects roughly 50 to 75 issuers per report (i.e., annually) for each large firm, and on average, less than three per report (i.e., triennially) for each small firms (Church and Shefchik 2012). ${ }^{9}$ The PCAOB uses a riskbased approach to selecting issuer clients for inspection by choosing audits evaluated to have a higher risk of material misstatement (RMM) primarily based on client-related factors such as issuer size and industry issues (i.e., pre-audit RMM), and it also considers auditor-related factors (e.g., auditor experience and inspection history) (PCAOB 2008, 2016a). ${ }^{10,11}$ With respect to the audits selected for inspection, the focus of the PCAOB is whether the audit was conducted in compliance with PCAOB standards as compared to the ex-post accuracy of the audit outcomes (PCAOB 2008, 2019; Church and Shefchik 2012).

Inspection results are shared in a report for the accounting firm. Part I of the report describes identified deficiencies in audits selected for inspection (but does not identify issuers). Part II of the report relates to an assessment of the firm’s overall system of quality control related to issuer audits, which is only publicly disclosed if the firm fails to sufficiently address the criticism within a one-year time frame from the date of the inspection report. The reports are publicly disclosed via the PCAOB’s website.

\footnotetext{
${ }^{9}$ I estimate in 2018 the PCAOB inspected roughly nine percent of U.S. public company issuers, based on a PCAOB report that it inspected approximately 530 US public company audits (700 total audits less 170 for non-US issuers) (PCAOB 2019) and data from Audit Analytics (i.e., approximately 6,010 US public company issuers in 2018). ${ }^{10}$ As stated by the PCAOB (2016a, 2), "risks may emanate, for example, from economic trends, company or industry developments, size of and changes between years in issuer market capitalization, and the audit firm, including audit partner and inspection history.” Thus, it appears the PCAOB's risk-based approach is largely based on non-strategic, pre-audit RMM, and also includes an element of auditor detection risk and other post-audit risk factors (e.g., audit partner and inspection history). In order to cleanly test the effects of risk-based inspections on auditor behavior (e.g., in isolation from individual reputation effects), my study focuses on effects of risk-based inspections based on pre-audit RMM. In Section V, I discuss the potential effects of relaxing this assumption.

${ }^{11}$ In recent years, the PCAOB has begun incorporating some random selections in addition to risk-based selections (PCAOB 2017, 2018). The PCAOB also focuses its inspections on the riskiest areas within the audit including areas that present the greatest challenges and most significant audit risks (PCAOB 2016a). In this study, I focus on the effects of the risk-based process to select issuer clients; however, I expect the theory used in this study to also generalize to the risk-based process to select inspection areas within the audit.
} 


\section{Hypotheses Development}

Regulatory inspections are independent, external quality reviews that induce accountability pressure - the expectation of being evaluated and suffering consequences for negative results (DeZoort and Lord 1997; Lerner and Tetlock 1999). Auditors expect that their audit work may be selected and evaluated by their regulators. Survey results in the U.S. indicate 100 percent of audit partners from large accounting firms $(n=107)$ have been inspected by the PCAOB on at least one of their audit engagements (Houston and Stefaniak 2013). Further, auditors anticipate suffering social and economic consequences from negative inspection results. Social consequences result from auditors’ individual inspection deficiencies being shared with their peers within their firms and from firm-wide inspection results being made publicly available in inspection reports. Economic consequences result from inspection deficiencies impacting auditors’ compensation and promotion status (Houston and Stefaniak 2013). In addition, in the U.S. the PCAOB has the authority to levy fines of up to $\$ 100,000(\$ 750,000)$ per person for unintentional (intentional) negligent acts, and can prohibit auditors from conducting audits of public companies (PCAOB 2003).

Given the potential consequences, regulatory inspections induce inspection risks, "the risk that an auditor or audit firm will suffer harm” as a result of inspections (Stefaniak et al. 2017, 151). Researchers and audit regulators have expressed concerns about inspection risks driving auditor effort, attention, and procedures (Glover and Prawitt 2013; Glover et al. 2014; Franzel 2013). That is, to manage inspection risks, auditors likely increase effort toward clients they anticipate have a higher likelihood of being inspected. Indeed, Houston and Stefaniak (2013) find that a majority of audit partners try to predict, ex ante, which engagements will be 
selected for PCAOB inspection and experimental evidence shows auditors allocate higher effort to clients with higher inspection risks (Stefaniak et al. 2017; Winn 2019).

Extending prior research to a multi-client setting, I expect resource-constrained auditors ${ }^{12}$ react to inspections differently depending on the client's misstatement risk. In risk-based inspections, and in my setting, clients with relatively higher misstatement risk ("higher-risk" clients) have a higher chance of being selected for inspection relative to others in the auditors' portfolios ("lower-risk" clients). Thus, in a risk-based inspections regime, I expect auditors' perceive inspection risks to be greater for higher- versus lower-risk clients. As a result, in an inspections regime, I expect auditors increase effort more for higher-risk clients to manage their perceived inspection risks. This discussion leads to the following interaction prediction of inspections and client risk on auditor effort in a setting with constrained audit resources:

H1: Relative to a regime without inspections, auditors in a risk-based inspections regime increase effort more for higher-risk clients than for lower-risk clients.

Further, I expect the joint effects of risk-based inspections and client risk on auditor effort predicted in $\mathrm{H} 1$ are mediated by auditors' perceived inspection risks. ${ }^{13}$

Moreover, I examine potential unintended effects of risk-based inspections on the quality of auditors’ decision performance. I expect auditors’ perceived inspection risks also induce taskrelated anxiety which threatens decision performance. Longstanding research finds an inverted-U

\footnotetext{
${ }^{12}$ I examine a setting with relatively high resource constraints because auditors often perform audits under such conditions. Much of the audit is typically performed during busy seasons when auditors have limited time and resources to complete above-average amounts of work and/or subject to tight budget constraints from client audit fee pressure (Lopez and Peters 2012). Supporting this conjecture, PCAOB members and other academics express concerns about the level of auditors' workload pressures (e.g., PCAOB 2013; Buchheit et al. 2016).

${ }^{13}$ In the auditing practice, it is difficult to disentangle the effects of auditors' perceived inspection risks, apart from wealth-maximizing behavior, on auditors' effort decisions (i.e., H1 predictions) and subsequently on their taskrelated anxiety and decision performance quality (i.e., H2 predictions). As described in Section III, by design, my setting holds constant the wealth-maximizing effects across conditions (for both $\mathrm{H} 1$ and $\mathrm{H} 2$ ), thereby enabling a cleaner test of the psychology-based effects, while also increasing tension for my hypotheses. Importantly, I also test the psychology-based mediation process model in supplemental analyses, which has implications for identifying mitigating mechanisms.
} 
relation between pressure and performance such that pressure increases attention and effort resulting in higher performance, but increasingly intense pressure also increases psychological arousal (e.g., anxiety) resulting in lower performance (Yerkes and Dodson 1908; Ashton 1990). Specifically, worry over adverse consequences due to strong pressures (e.g., incentives or motivations) induces task-related anxiety, a temporary stress response (Hutt and Weidner 1993), which negatively affects judgment performance (Ashton 1990; DeZoort and Lord 1997).

For example, Stone and Kadous (1997) find that increasing the importance of decision outcomes from enhanced monitoring combined with increasing perceived time pressure causes task-related anxiety. Similarly, I expect increasing the importance of audit-related decisions from penalty-based regulatory inspections (i.e., inspection risks) in an environment with constrained audit resources induces task-related anxiety. That is, if resource-constrained auditors are unable or unwilling to increase auditor effort to desired levels to manage inspection risks, in addition to increasing effort, inspections may also induce task-related anxiety (Ashton 1990). Indeed, audit partners in the U.S. report that PCAOB inspections have increased their workload resource pressure due to added documentation and auditing requirements (i.e., likely affecting their ability to sufficiently increase effort), and also that they are not able to increase audit fees to fully recover increases in auditor effort due to inspections (i.e., likely affecting their willingness to sufficiently increase effort) (Houston and Stefaniak 2013). Likewise, anecdotal examples about auditors' perceived inspection risks reflect increased auditor anxiety. One U.S. audit partner notes that PCAOB inspections "put the engagement personnel under tremendous pressure due to the ramification of significant findings" (cf. Houston and Stefaniak [2013, 39]) and other audit partners in the U.S. and Australia report that the nature of regulatory inspections are perceived to be "adversarial” (Houston and Stefaniak 2013, 30) and "coercive” or antagonistic (Dowling et al. 
2015, 6). Finally, inspection-risk-induced anxiety may have contributed to several audit practice leaders and partners from one Big-4 firm illicitly obtaining confidential information from the PCAOB about planned inspections in an attempt to avoid inspection findings, leading to criminal prosecutions (Michaels and Rapoport 2017; Cohn 2019; Whitehouse 2019).

To posit how task-related anxiety affects auditors' decision performance in a multi-client setting, I draw on attentional control theory with a dual-task paradigm from psychology (Eysenck et al. 2007). Theory suggests task-related anxiety interrupts individuals' decisionmaking processing by impairing the use of goal-directed processing and increasing the use of stimulus-driven processing. Specifically, it narrows individual's attention toward the threatrelated stimuli and away from other less-salient tasks, creating a spotlight effect. For threatrelated tasks (e.g., higher-risk clients in a risk-based inspections regime), impairments from anxiety on decision performance may be offset by increased attention and perceived importance of the task. Thus, I make no predictions as to whether or not risk-based inspections will affect auditors' decision performance for higher-risk clients. However, for less-salient tasks out of the spotlight (e.g., lower-risk clients in a risk-based inspections regime), following prior research (e.g., Adelberg and Batson 1978; Ashton 1990; Eysenck et al. 2007), I expect task-related anxiety impairs auditors' decision performance such that it increases their use of suboptimal, heuristic-based, high-risk decision strategies resulting in more instances of low-quality decisions. Thus, I predict the following interaction of inspections and client risk on auditors' decision performance in a setting with constrained audit resources:

H2: A risk-based inspections regime impairs auditors' decision performance for lowerrisk clients relative to a regime with no inspections and relative to higher-risk clients within an inspections regime, ceteris paribus.

Further, I expect the joint effects of risk-based inspections and client risk on auditors' decision performance in $\mathrm{H} 2$ are mediated by auditors' perceived inspection risks and task-related anxiety. 


\section{METHOD}

\section{Design Overview}

I conduct a $2 \times 2$ mixed-design experiment, manipulating client risk (lower and higher) within-participant and risk-based inspections (absent in the No Inspections condition or present in the Inspections condition) between-participants. ${ }^{14}$ I operationalize client risk such that higher(lower-) risk clients have a higher (lower) probability of containing a misstatement in the financial statements (i.e., pre-audit misstatement risk). I model the inspections regime after the PCAOB’s inspections process. In the Inspections condition, participants are subject to independent reviews; the reviews are selected using a risk-based approach such that, if reviewed, clients with relatively higher misstatement risks have a higher probability of being selected for review; penalties are incurred for insufficient levels of effort; and penalties are publicly disclosed. Participants make audit effort and reporting decisions for higher- and lower-risk clients over repeated independent periods.

\section{Experimental Procedures}

The experiment was conducted in a controlled laboratory with 105 undergraduate student participants from a large state university. The experiment follows the principles of experimental economics to create a setting that captures the key incentives in natural auditing environments, such that the incentives in the study are designed to parallel those in the audit practice (e.g., King 2002; Bowlin 2011; Bowlin et al. 2015). To control for confounding factors unrelated to this study, participants are randomly assigned to one of the inspections conditions and the experimental setting is made as stark as possible using neutral language (King 1991; Haynes and Kachelmeier 1998; Kachelmeier and King 2002). Participants are assigned the role of “verifiers” (auditors) and the other audit market players are referred to as "sellers” (clients), "buyers”

\footnotetext{
${ }^{14}$ Institutional review board approval was received for all experiments prior to data collection.
} 
(investors), and “a review board” (regulators). Further, clients' financial statements are labeled “assets:” “Type A assets” for lower-risk clients and “Type B assets” for higher-risk clients. To reduce the complexity of the audit market, clients', investors', and regulators' behaviors are computerized (Schatzberg and Sevcik 1994). ${ }^{15}$ Importantly, the experimental design allows for testing my psychology-based predictions about the effects of inspections on auditor behavior in a controlled, multi-client setting that captures the key incentives in natural audit environments, thereby allowing my theory and experimental results to generalize to the audit practice.

Prior to beginning the experiment, participants were provided with written instructions. The experimenter read aloud a summarized version of the instructions to the participants, highlighting the key points of the experiment. Participants were assigned the role of a "verifier" asked to make decisions for 20 independent periods. The instructions familiarized participants with the setting of the experiment, the choices to be made, the programmed behavior of the other players, and the nature of the payoffs for different outcomes. The experiment was implemented using the z-Tree experimental software (Fischbacher 2007).

\section{The Experimental Setting}

The following describes the sequence of the steps in the experiment. A flowchart of the participants' decisions related to these experimental steps is included in Appendix B, Panel A. Verifiers make repeated effort and reporting decisions in a setting with constrained effort resources and accumulate experimental earnings (EE) over 20 periods. ${ }^{16}$ The design choices

\footnotetext{
${ }^{15}$ The theoretical predictions across the inspections conditions remain unchanged if actual participants are used for clients, investors, and/or regulators. The auditor participants have full information as to how the other parties' decisions are programmed. Consistent with single-period settings, the other parties' decisions are independent from prior periods. These design choices remove strategic interaction and reputational effects that may arise between auditors and other parties, thereby allowing for a cleaner test of the theoretical predictions.

${ }^{16}$ Participants were made aware in advance there would be 20 periods. The pattern of means in period 20 for both Auditor Effort and Auditors' Low-Quality Decisions mirror those reported for all 20 periods, suggesting there was not a significant end-of-game effect.
} 
outlined below are designed to capture the key concepts and incentives in natural auditing

environments, which are summarized in italics following each experimental step.

Experimental Steps:

1. Asset types. At the start of each period, verifiers receive revenues of 1,000 EE per asset to verify the values of one Type A asset and one Type B asset. For Type A assets, the probability of a low (high) value is $0.20(0.80)$. For Type B assets, the probability of a low (high) value is $0.40(0.60)$.

\section{Higher-(lower-) risk clients have a higher (lower) pre-audit risk of material misstatement in financial statements.}

2. Effort-level choices. Verifiers make effort-level choices by allocating a fixed amount of resources among the two assets and keeping the remainder for their personal consumption. Verifiers are informed that the standard level of effort per asset is 3 , but that they can allocate any amount greater than or equal to 1 for each asset, subject to the constraint that the total level of effort for both assets does not exceed $6 .{ }^{17}$ Higher levels of effort cost more but also provide a more accurate signal if the true value of the asset is low.

Auditors have constrained resources, especially during year-end audits. Effort is costly but increases the chances of detecting material misstatements.

3. Asset value signals. Verifiers receive an imperfect signal about the true value of the asset (high, low). When the true value of the asset is low, higher levels of effort decrease the probability of receiving an incorrect high-value signal (referred to as the "error rate"). ${ }^{18}$ When the true value of the asset is high, the error rate is relatively low and is independent from effort. Verifiers are informed that the probability of a "high-value" signal being

\footnotetext{
${ }^{17}$ I constrain the total effort to " 6 " in order to create relatively high resource constraints based on pilot study results. In a pilot study with no restrictions on the total audit resources, participants' average total effort was 7.11 in the No Inspections condition. Thus, the setting resembles a busier season similar to when year-end audit procedures are being performed. In this setting, auditors have sufficient levels of resources to meet the firm's optimal standards, but do not have extra resources. The "standard" effort level of 3 equals the wealth-maximizing level under the assumption that audit firms' standard levels of effort are the level at which the firm maximizes profits. A more detailed discussion on the wealth-maximizing decisions is included in the next section. As described in Section IV, in a supplementary study, I increase the maximum amount of total effort to 7 and reperform analyses in a setting with relatively lower resource constraints. As theory predicts, results are sensitive to the level of resource constraints (see Tables A3 and A4 in the Online Appendix for results).

${ }^{18}$ As shown in Panel A of Exhibit 1, the error rates for low-value assets range from 12 to 40 percent for higher-risk clients and from 6 to 20 percent for lower-risk clients. Depending on the effort-level choices, the error rates are not always higher for higher-risk versus lower-risk clients, consistent with prior research on risk-based auditing (Bowlin 2011). The error rates represent the actual level of post-audit risk, which are always greater than zero, but never known due to uncertainty (Knechel et al. 2013). Further, to account for uncertainty in detecting Type II errors, as discussed in Step 4, there is only a 50 percent chance that incorrect high reports will be detected. Alternate error rates could have been chosen; I expect my results of inspections on auditor behavior are robust to varying error rates because theory predicts changes in behavior result from inspection risks which are based on auditor effort decisions rather than ex-post audit report outcomes.
} 
incorrect if the true value of the asset is low is equal to the error rate for their effort-level choice and that the probability of a "low-value" signal being incorrect (accurate) is 10 (90) percent. ${ }^{19}$ The table detailing the error rates for low-value assets provided to participants is included in Panel A of Exhibit 1.

\section{[Insert Exhibit 1 about here]}

The risk of failing to identify a material misstatement in the financial statements when one exists (i.e., a Type II error) depends on the level of auditor effort. The risk of identifying a material misstatement in the financial statements when one does not exist is relatively low (i.e., a Type I error). Nonetheless, Type I errors occur due to uncertainty about the materiality of the identified misstatement in the financial statements.

4. Reporting choices and outcomes. For each asset, verifiers report whether the asset has a high or low value. If the verifier reports that the asset has a low value, they are charged a flat cost of $500 \mathrm{EE}$ for "disagreeing with the seller," regardless of the outcome. If the verifier reports that the asset has a high value (i.e., agrees with the seller), the report cost depends on the true value of the asset. If the true value of the asset is high, there is no report cost. If the true value of the asset is low, there is a 50 percent chance that the incorrect high report will be detected and charged an incorrect report cost of 6,000 EE. If the incorrect high report is not detected, there is no report cost.

Given uncertainty, auditors have incentives to give in to their clients' preferences to not report misstatements. However, auditors have stronger incentives to avoid being detected for unreported material misstatements. Due to uncertainty, material misstatements often go unreported and undetected. Costs associated with detected Type II errors are significant (i.e., litigation and reputational damage costs).

5. Review process. Half of the verifiers are subject to reviews by a review board. In each period there is a 50 percent chance that one of their assets will be reviewed and there is a 0.05 (0.95) probability that their Type A (Type B) asset will be reviewed. ${ }^{20,21}$ When the verifier is selected for review, s/he is charged a cost of $150 \mathrm{EE}$ for the review and s/he incurs penalties from 150 EE for "severe" to 75 EE for "moderate" to 0 EE for "none" based on their effort-level choice for that asset. ${ }^{22,23}$ Participants are informed that at the

\footnotetext{
${ }^{19}$ As described in Section IV, in a preliminary study, low-value signals are 100 percent accurate. I find that the tests of hypotheses are robust to this design choice (see Tables A1 and A2 in the Online Appendix for results).

${ }^{20}$ In the PEQ, 45 of the 47 participants (95.7 percent) accurately indicated that if they were selected for review, “Type B assets had a much larger chance of being reviewed than Type A assets (95\% versus 5\%).” Reported results are inferentially identical if the two participants who failed this comprehension check are excluded from analyses.

${ }^{21}$ Thus, in any period, there is a 47.5 (2.5) percent chance that participants' higher-risk (lower-risk) client will be inspected. While predicting whether a client will or will not be selected for inspection may be easier in my setting than for auditors in natural settings, a strong manipulation of risk-based selections allows for examining differences in auditor behavior for clients with varying levels of misstatement risk under a risk-based process. Similar to my setting, I expect auditors in natural auditing environments try to anticipate that certain clients in their portfolio are more or less likely to be selected if inspected (Houston and Stefaniak 2013).

${ }^{22}$ Review penalties are the same for both client types and the economic consequences associated with review penalties are relatively small in my setting; whereas, PCAOB inspection penalties are sometimes high and may differ for clients with varying levels of risk. Based on my theory, I expect that higher economic penalties would
} 
conclusion of the experiment, the review board (the experimenter) will announce each person's review penalties to the group, one by one in order of severity (highest to lowest amounts). ${ }^{24}$ The table of the review penalty costs provided to the participants is included Panel B of Exhibit 1.

Individual auditors have a chance of being selected for inspection in any given year. Under the PCAOB's risk-based approach, auditors can anticipate that clients with a higher risk of material misstatement are more likely to be selected for inspection. Auditors incur time and costs with inspections, regardless of the inspection outcomes. $P C A O B$ inspections identify deficiencies in the audit process (i.e., whether the audit complies with the PCAOB standards) rather than in the ex-post audit outcomes. Auditors incur economic and social consequences from PCAOB inspection deficiencies.

6. Feedback. Verifiers receive feedback about the asset values, report outcomes, review results, and earnings for the period. Then, the next period begins and the procedures are repeated.

To enhance comparability, for each period I randomly predetermined the states of the assets and reviews based on the probability parameters disclosed to the participants in the instructions and I held these states constant across the inspections conditions and for all experimental sessions. The predetermined states each period include: (1) the true values of the assets, (2) the signals for each level of effort, (3) whether or not an incorrect high report will be detected, (4) whether or not a review will take place, and (5) the asset that will be reviewed. Prior to the start of the experiment, participants completed a computerized true-false pretest to increase auditors' perceived inspection risks and task-related anxiety, which would likely lead to similar or amplified effects on auditor behavior (auditor effort and auditors' decision performance quality).

${ }^{23}$ The auditor's wealth-maximizing decision is an effort-level of 3, but auditors receive inspection penalties for anything lower than the maximum effort-level choice. This design choice increases inspection risks and represents an expected gap between the levels of audit work required to maximize the firm's profits versus that required to meet audit regulators' standards. My assumption is based on PCAOB inspection findings indicating that only about 5 percent of inspection deficiencies impact auditors' report conclusions (i.e., result in restatements) (Church and Shefchik 2012; Hermanson, Houston, and Rice 2007) and that approximately 84.0 percent of inspection deficiencies are non-misstatement related (e.g., deficiencies result from failures to sufficiently document audit work or failures to sufficiently evaluate audit procedures) (Church and Shefchik 2012). Thus, while inspection deficiencies identify failures to meet the PCAOB's standards, the vast majority do not impact the accuracy of auditors' conclusions. That said, in my setting the economic penalties are decreasing with higher effort-levels, which is presumably similar to natural auditing environments.

${ }^{24}$ I chose to announce the penalties one at a time at the end of the experiment due to time constraints of the experiment. In the PEQ, participants in the Inspections condition were asked to what extent they were "worried about others learnings about review penalties you incurred.” The response to this measure is significantly positively associated with participants’ Perceived Inspection Risks for higher-risk clients $\left(\mathrm{F}_{1,44}=2.963\right.$, $\mathrm{p}=0.046$ one-tailed) as well as participants' Task-Related Anxiety $\left(\mathrm{F}_{1,44}=7.438, \mathrm{p}=0.005\right.$ one-tailed), suggesting a successful manipulation of the social consequences of inspections. 
ensure they understood the key points of the study and the experimental manipulations. ${ }^{25}$ Then, participants completed three practice periods to help understand the experimental protocol, become familiar with the computerized software, and understand how their decisions influence their outcomes and payoffs.

Following the experiment, participants completed a post-experimental questionnaire (PEQ) with questions about demographics, comprehension questions, insights into how participants made their effort and reporting decisions, and other control variables (e.g., individual risk preferences, interest in the study, age, gender, etc.). ${ }^{26}$ Participants were paid in cash at the end of the study. The average payment was $\$ 19.55$, ranging from $\$ 5$ to $\$ 31$, and did not significantly differ across the inspections conditions. ${ }^{27}$ The experiment lasted approximately 60 minutes, ranging from 50 to 80 minutes.

\section{Wealth-Maximizing Behavior}

\footnotetext{
${ }^{25}$ Participants completed five (eight) true and false questions in the No Inspections (Inspections) condition about the details of allocating effort, the signals of the true asset values, the details of incorrect reports, and the review process. After answering each question, participants were provided with details about the correct answer.

${ }^{26}$ Participants were randomly assigned to inspections conditions. None of the control variables significantly differ across the inspections conditions ( $p$-values $>0.30$ ) consistent with successful randomization. Female gender is positively associated with the decision performance dependent measure $\left(\mathrm{t}_{190}=2.147, \mathrm{p}=0.033\right)$, but including gender as a covariate in the analyses has no impact on the inferences from the decision performance results. Individual risk preferences is positively associated with the auditor effort dependent measure $\left(\mathrm{F}_{1,72}=4.993, \mathrm{p}=\right.$ 0.029), but including individual risk preferences as a covariate in the analyses has no impact on the inferences from the auditor effort results. Individual risk preferences are elicited using the Holt and Laury (2002) task, a prevalent measure of risk attitudes. Participants were paid based on the outcome of their decisions. A weakness of this method is that the task is relatively complex and can confuse participants (Charness, Gneezy, and Imas 2013). However, on average, it appears participants overcame this limitation as participants' risk preferences are positively associated with their auditor effort decisions $\left(\mathrm{F}_{1,72}=5.311, \mathrm{p}=0.024\right)$.

${ }^{27}$ All participants were informed of the same expected average total compensation and were provided with a conversion rate from EE to dollars. In an attempt for participants to earn similar payments, on average, across the experimental conditions, I used different conversion rates across the inspections conditions (unbeknown to participants). Given the high cost of detected incorrect reports, there was potential for participants to accumulate negative earnings (i.e., end in bankruptcy). The percentage of participants who went bankrupt did not significantly differ across the Inspections (mean $=12.8$ percent) and No Inspections conditions (mean $=16.3$ percent, $t_{94}=0.490$, $\mathrm{p}=0.626$ ). For participants who went bankrupt, I informed them after the experimental task was complete that they would earn $\$ 0$ for the experimental task and that they would not be required to pay any additional amounts for the negative earnings. All tests of hypotheses are robust to controlling for bankruptcy position and excluding period observations in which the participant was in a bankruptcy position with one exception. When excluding bankruptcy position observations, in tests of $\mathrm{H} 2$, the follow-up planned contrast test of Inspections on Auditors' Low-Quality Decisions for lower-risk clients is directionally consistent but slightly weaker $\left(\mathrm{t}_{177}=1.198\right.$, one-tailed $\left.\mathrm{p}=0.116\right)$.
} 
As described above, I use economic incentives in my setting to mimic the key incentives in natural auditing environments. However, to better isolate my predicted psychology-based effects from economics-based effects, I also construct a setting where the wealth-maximizing predictions are held constant across the experimental conditions. First, regarding effort decisions, the inspection review process does not alter the wealth-maximizing decisions. As shown in Exhibit 1, while higher levels of effort reduce economic review penalties if selected for review, the incremental economic costs for higher levels of effort are always greater than the expected economic benefits of lower review penalties. ${ }^{28}$ Additionally, I design the wealth-maximizing effort-level decision to be the standard effort-level choice 3 for both higher- and lower-risk clients. ${ }^{29}$ Second, regarding reporting decisions (high/low), the inspection review process also does not alter the wealth-maximizing decisions because review penalties are based on effortlevel choices rather than on report outcomes. Additionally, I design the wealth-maximizing reporting decisions to be to always follow the signal for both higher- and lower-risk clients. ${ }^{30}$ In summary, the wealth-maximizing decisions for both client types and in both Inspections conditions are to always choose an effort-level of " 3 " and to report according to the signal such that there would be no instances of low-quality reporting decisions. Thus, in my setting, any difference across conditions in effort (i.e., H1 predictions) or low-quality reporting decisions (i.e., $\mathrm{H} 2$ predictions) is inconsistent with wealth-maximizing behavior.

\footnotetext{
${ }^{28}$ To clarify, the expected economic benefits of lower review penalties for higher effort-level choices are calculated using an expected 0.50 probability of being selected for review in each period and additionally a $0.95(0.05)$ probability of having higher- (lower-) risk clients being reviewed if selected.

${ }^{29}$ Specifically, as shown in Panel A of Exhibit 1, for both clients the cost of effort has increasing net marginal benefits (i.e., accuracy of the signal in order to avoid high incorrect report costs) from effort-levels 1 to 3 , but beyond 3, the marginal benefits begin to decline. Further, the effort-level choice 3 for higher-risk and 3 for lowerrisk clients yields the smallest combined signal error rate (24 percent) and risk of failure to detect a low-value asset.

${ }^{30}$ Appendix B illustrates the expected costs of the various report choices for lower-risk (Panel B) and for higher-risk (Panel C) clients following each type of signal. As shown in Lines D, reporting according to the signal always yields the lowest expect cost, especially upon receiving a low-value signal which is relevant for auditors' low-quality decisions in tests of $\mathrm{H} 2$.
} 


\section{Comprehension Check}

In the PEQ, 96 of 105 (91.4 percent) participants correctly responded to a question supporting their understanding of the consequences associated with issuing an incorrect high report (i.e., that there was a 50 percent chance of incurring a 6,000 EE penalty). Given the importance of this understanding for the decision performance dependent measure, I exclude the nine participants who failed the comprehension check from the analyses; however, results remain inferentially consistent if all participants are included. The resulting sample includes 96 participants with 49 in the No Inspections and 47 in the Inspections conditions, respectively.

\section{Dependent Variables}

Auditor effort is measured as participants' effort-level choice for lower- and higher-risk clients, ranging from 1 to 5, subject to a constraint that total auditor effort does not exceed 6 (n $=$ 3,840 client-period observations). ${ }^{31}$ Auditors' decision performance is measured with Auditors ' Low-Quality Decisions for lower- and higher-risk clients, a binary variable equal to 1 if the participant issues a high report after receiving a low-value signal (regardless of the outcome), and 0 otherwise. Because this type of low-quality decision can only be made after receiving a low-value signal, for tests of H2, I restrict the sample to client-period observations with lowvalue signals $(\mathrm{n}=1,325) .^{32}$

The dependent measure for auditors’ decision performance has several benefits. First, it is consistent with auditors’ willingness to give in to client-preferred incentives and, more importantly, it captures low-quality decisions consistent with theory underlying H2 (e.g.,

\footnotetext{
${ }^{31}$ Auditor effort results and tests of $\mathrm{H} 1$ are inferentially identical when (1) restricting the sample to the latter 10 periods and (2) using average auditor effort over the 20 periods as the dependent measure (i.e., one independent observation per participant) and performing repeated-measures ANCOVA.

${ }^{32}$ Auditors' decision performance results and tests of $\mathrm{H} 2$ are inferentially identical when (1) using all client-period observations ( $n=3,840)$ and controlling for signal type (low or high) and (2) using participant's total number of low-quality decisions as a percentage of low-value signals over the 20 periods as the dependent measure (i.e., one independent observation per participant) and performing repeated-measures ANCOVA.
} 
suboptimal, more heuristics-based, more high-risk decisions). To explain, participants incur a cost of $500 \mathrm{EE}$ for reporting the asset has a low value for "disagreeing with the seller" versus 0 EE for reporting the asset has a high value. However, participants also face an expected cost of 2,700 EE for issuing a high report after receiving a low-value signal (i.e., 90 percent accurate signal $\times 50$ percent chance of being detected $\times 6,000 \mathrm{EE}$ cost for detected incorrect high reports). Thus, reporting high after receiving a low-value signal is a suboptimal, high-risk, low-quality decision. However, due to uncertainty in the signal and report outcome, the decision does not necessarily reflect irrational behavior or intentional misreporting. Second, restricting the sample to observations with low-value signals allows for a ceteris paribus test of low-quality decisions across the experimental conditions (i.e., the expected outcome of reporting high after receiving a low-value signal is independent from client risk, auditor effort, and inspection condition).

\section{Mediation Process Model Variables}

The mediation measures are elicited following auditors' decisions in the final period of the task. Perceived Inspection Risks is measured as participants' perceived importance and pressure for decisions related to each client using the following questions with 11-point likert scales: (1) "How important was it to you to make accurate reporting decisions for each asset type (Type A and Type B assets)?;” (2) “To what extent did you feel pressure to choose an effortlevel of 3 or more for each asset type (Type A and Type B assets)?;” and (3) “To what extent did you feel pressure to make accurate reporting decisions for each asset type (Type A and Type B assets)?” Principle components analysis with varimax rotation finds the three questions load onto a single factor that explains 63 (73) percent of the variation for lower-risk (higher-risk) clients. Thus, a composite measure of the factors is used as auditors' Perceived Inspection Risks for lower- and higher-risk clients. Task-Related Anxiety is measured with one question: "Please 
indicate how you felt while making your decisions during the experiment" from (1) "relaxed" to

(5) “nervous,” following Stone and Kadous (1997). ${ }^{33}$

\section{Control Variables}

I control for potential time-series effects over the 20 repeated periods by including Period as a covariate in all analyses. The data was collected over two academic semesters, "sessions." Session unexpectedly influences Auditors' Low-Quality Decisions for higher-risk clients ( $\mathrm{t}_{94}=$ 2.545, $\mathrm{p}=0.013)$, Perceived Inspection Risks for lower-risk clients ( $\left.\mathrm{t}_{94}=2.738, \mathrm{p}=0.007\right)$, and auditors' Task-Related Anxiety ( $\left.\mathrm{t}_{94}=2.932, \mathrm{p}=0.004\right)$. Accordingly, I control for the effects of Session by including it as a covariate in all analyses. ${ }^{34}$

\section{RESULTS}

\section{Tests of Hypotheses}

\section{[Insert Figure 1 and Table 1 about here]}

\section{Auditor Effort}

Hypothesis 1 predicts that relative to a regime without inspections, auditors in a risk-

based inspections regime will increase auditor effort more for higher-risk clients than for lowerrisk clients. Auditor Effort condition means (adjusted) are graphed in Panel A of Figure 1 and descriptive statistics are tabulated in Panel A of Table $1 .^{35}$ I test the joint effects of inspections and client risk on auditor effort using a linear mixed-effects regression model (Panel B of Table

\footnotetext{
${ }^{33}$ Consistent with Stone and Kadous (1997), I also assess participants' positive affect by asking how participants felt while making their decisions from "drowsy" (1) to "excited" (5), and find that the manipulation of inspections did not unintentionally influence positive affect $\left(\mathrm{t}_{94}=0.496, \mathrm{p}=0.621\right)$.

${ }^{34}$ All tests of hypotheses are inferentially identical without including Period and Session as covariates. Descriptive statistics for the dependent and mediation measures across Session are included in the Online Appendix (see Table A5, Panels A-D).

${ }^{35}$ All analyses are adjusted for Period and Session. Unadjusted means of Auditor Effort follow a similar pattern as reported means. In the No Inspections condition, the mean for lower-risk clients is 2.410 and the mean for higherrisk clients is 2.571. In the Inspections condition, the mean for lower-risk clients is 2.265 and the mean for higherrisk clients is 3.377. Also, see Table A6 in the Online Appendix for results of the distribution of total auditor effort across the inspections conditions for the main study (Panel A) and the preliminary study (Panel B). As discussed in the notes to Table A6, results suggest participants in the Inspections condition could increase effort for higher-risk clients without having to decrease effort for lower-risk clients, on average.
} 
$1)^{36}$ and follow-up planned contrasts from the model (Panel C of Table 1). A mixed-effects

model is used because it includes a random intercept for each participant which allows for testing the fixed effects (i.e., the manipulated independent variables and covariates) on auditor effort while adjusting for the correlation due to repeated observations for each participant (i.e., for the two clients over 20 periods) (Verbeke 1997).

Consistent with H1, for higher-risk clients, Auditor Effort is significantly higher in the Inspections $($ mean $=3.377)$ versus No Inspections condition $($ mean $=2.539, \mathrm{p}<0.001)$; whereas, for lower-risk clients, Auditor Effort does not significantly differ across the Inspections (mean = 2.265) and No Inspections conditions (mean $=2.397, \mathrm{p}=0.272$ ). Further, the effect of inspections for higher-risk clients is significantly greater than that for lower-risk clients evidenced by the significant Inspections $\times$ Client Risk effect on Auditor Effort $(\mathrm{p}<0.001)$. Results support $\mathrm{H} 1 .^{37,38}$

\section{Auditors' Decision Performance}

Hypothesis 2 predicts that a risk-based inspections regime impairs auditors’ decision performance for lower-risk clients relative to a regime with no inspections and relative to higherrisk clients within an inspections regime, ceteris paribus. Auditors' decision performance is measured as Auditors' Low-Quality Decisions, a binary variable equal to 1 if the participant

\footnotetext{
${ }^{36}$ See Table A7, Panel A, in the Online Appendix for results of Auditor Effort with fixed effects outputs, similar to ANCOVA.

${ }^{37}$ Due to the stylized setting of this experiment whereby the wealth-maximizing level of effort is held constant at 3 for both higher- and lower-risk clients, my setting does not allow for a realistic comparison of auditor effort across client-risk groups. Thus, I do not necessarily expect a main effect of client risk on auditor effort, which is inconsistent with audit research and practice (e.g., Knechel 2007; Bowlin 2011). However, my setting does allow for realistically comparing changes in auditor effort from a regime with no inspections to a regime with inspection within and across client risk types (tests of $\mathrm{H} 1$ ).

${ }^{38} \mathrm{H} 1$ is also supported using a structural equations model that simultaneously tests the effect of Inspections separately for higher- and lower-risk clients and tests the difference in the effect of inspections across the two clientrisk groups. The model includes clustered robust standard errors for participants to adjust for repeated measures for each participant (i.e., two clients and 20 periods). Results show Inspections significantly increase Auditor Effort for higher-risk clients (std. coef. $+0.402, \mathrm{t}=5.928, \mathrm{p}<0.001$ ), Inspections do not significantly affect Auditor Effort for lower-risk clients (std. coef. $-0.072, \mathrm{t}=-0.859, \mathrm{p}=0.390$ ), and the difference in the effect of Inspections on clientrisk groups is significant $\left(X_{(1)}^{2}=19.163\right.$, p-value $\left.<0.001\right)$.
} 
issues a high report after receiving a low-value signal, and 0 otherwise. Auditors' Low-Quality

Decisions condition means (adjusted) as a percentage of low-value signals are graphed in Panel B of Figure 1 and descriptive statistics are tabulated in Panel A of Table 2. ${ }^{39}$

\section{[Insert Table 2 about here]}

I test the joint effects of inspections and client risk on auditors’ low-quality decisions using a generalized linear mixed-effects logistic regression model (Panel B of Table 2) ${ }^{40}$ and follow-up planned contrasts from the model (Panel C of Table 2). The mixed-effects model includes a random intercept for each participant, thereby adjusting for the correlation due to repeated observations for each participant (i.e., for the two clients over 20 periods). The effect of inspections on auditors’ low-quality decisions significantly differs for higher- and lower-risk clients evidence by the significant Inspections $\times$ Client Risk effect on Auditors' Low-Quality Decisions $(\mathrm{p}=0.021)$. H2 is formally tested with two follow-up planned contrasts tests. First, for lower-risk clients, Auditors' Low-Quality Decisions is higher in the Inspections (mean = 0.151) than in the No Inspections condition (mean $=0.073, \mathrm{p}=0.064$ ) with marginal significance. Second, in the Inspections condition, Auditors' Low-Quality Decisions are significantly greater for lower-risk clients $($ mean $=0.151)$ than for higher-risk clients $($ mean $=0.091, p=0.013)$, ceteris paribus. Together, results provide support for H2.

\section{Additional Analyses}

\section{Replication of Results in a Preliminary Study}

\footnotetext{
${ }^{39}$ All analyses are adjusted for Period and Session. Unadjusted means of Auditors' Low-Quality Decisions follow a similar pattern as reported means. In the No Inspections condition, the mean for lower-risk clients is 0.088 and the mean for higher-risk clients is 0.103. In the Inspections condition, the mean for lower-risk clients is 0.142 and the mean for higher-risk clients is 0.060 .

${ }^{40}$ See Table A7, Panel B, in the Online Appendix for results of Auditors' Low-Quality Decisions with fixed effects outputs, similar to ANCOVA.
} 
All tests of hypotheses are replicated in a preliminary study with 44 participants. Auditor Effort results ( $\mathrm{n}=1,760$ client-period observations) and Auditors' Low-Quality Decisions results ( $n=618$ client-period observations with low-value signals) are graphed in Figure 1 and tabulated in the Online Appendix (see Tables A1 and A2). Supporting H1, linear mixed-effects regression and follow-up planned contrast results of Auditor Effort show Inspections significantly increase Auditor Effort for higher-risk clients (mean diff. $+0.815, \mathrm{p}<0.001$ ), but Inspections have an insignificant effect on Auditor Effort for lower-risk clients (mean diff. $=-0.169, \mathrm{p}=0.312$ ), and the effect of inspections across client-risk groups is significant evidenced by the Inspections $\times$ Client Risk effect (est. 0.985, $\mathrm{p}<0.001$ ). Linear mixed-effects logistic regression results of Auditors' Low-Quality Decisions show a significant Inspections $\times$ Client Risk effect (coef. 2.127, $p=0.017$ ). Supporting H2, follow-up planned contrasts from the model show for lower-risk clients, Auditors' Low-Quality Decisions is significantly greater in the Inspections (mean = 0.193 ) than in the No Inspections condition (mean $=0.024$, one-tailed $\mathrm{p}=0.006$ ); and, in the Inspections condition, Auditors' Low-Quality Decisions is significantly greater for lower-risk (mean $=0.193)$ than higher-risk clients $($ mean $=0.075$, one-tailed $\mathrm{p}=0.017)$.

The experimental method used in this preliminary study is identical to the main study with the exception that a low-value signal is 100 (versus 90) percent accurate. Because the main study includes uncertainty in low-value signals, it better allows for capturing the theoretical construct of low-quality decision performance consistent with suboptimal, heuristics-based, high-risk decisions. Whereas, the dependent measure in the preliminary study is more consistent with strategic gaming behavior (in addition to more suboptimal, heuristics-based, high-risk decisions) because low-quality decisions also reflect intentional misreporting in the absence of uncertainty in low-value signals. To further mitigate concerns that $\mathrm{H} 2$ results are due to strategic 
gaming behavior and/or intentional misreporting, the main study also captures participants' decision-making processing which allows for a better test of the underlying theory.

\section{Mediation Process Model Results}

I perform mediation process model analyses to provide additional support for my theoretical framework and to help rule out the potential alternate explanation related to strategic gaming behavior and/or intentional misreporting. ${ }^{41}$ The theoretical framework predicts that riskbased inspections increase auditors' perceived inspection risks for higher-risk clients resulting in increased effort for higher-risk clients (H1), but also that perceived inspection risks increase auditors' task-related anxiety resulting in impaired decision performance for lower-risk clients (H2). Descriptive statistics of the mediation measures by condition are reported in Table 3. As expected, the mean Perceived Inspection Risks, a composite measure of participants' perceived importance and pressure for decisions related to each client, is highest in the Inspections condition for higher-risk clients, and the mean Task-Related Anxiety is higher in the Inspections than in the No Inspections condition. ${ }^{42}$

\section{[Insert Table 3 and Figure 2 about here]}

Process model results are presented in Figure 2 for Auditor Effort (Panel A) and Auditors' Low-Quality Decisions (Panel B). ${ }^{43}$ As reported in Figure 2, the process models have good fit

\footnotetext{
${ }^{41}$ The potential alternate explanation that $\mathrm{H} 2$ results are due to strategic gaming behavior and/or intentional misreporting does not support a significant Inspections $\times$ Client Risk effect on Auditors' Low-Quality Decisions. That is, Auditors' Low-Quality Decisions for lower-risk clients due to strategic gaming behavior or intentional misreporting should not differ across the inspections conditions because auditors' reporting decisions and potential outcomes are identical in both inspections conditions.

${ }^{42}$ Consistent with theory, repeated-measures ANCOVA (i.e., controlling for Session) reveals a significant Inspection $\times$ Client Risk effect on auditors' Perceived Inspection Risks $\left(\mathrm{F}_{1,93}=12.974, \mathrm{p}=0.001\right)$ and follow-up simple effects tests shows a significant effect of Client Risk within the Inspections condition $\left(\mathrm{F}_{1,93}=12.607\right.$, one-tailed $\left.\mathrm{p}<0.001\right)$ such that auditors' Perceived Inspection Risks are significantly greater for decisions related to higher-risk clients than for lower-risk clients. The difference in auditors' Task-Related Anxiety across the inspections conditions is not statistically significant $\left(\mathrm{F}_{1,93}=0.733\right.$, one-tailed $\left.\mathrm{p}=0.199\right)$; however, theory suggests auditors' perceived inspection risks leads to task-related anxiety, which is tested in the process model in Panel B of Figure 2.

${ }^{43}$ The process model analyses include data at the participant-summary level versus the period level because the mediating variables are composite measures collected at the end of the study. As such, Auditor Effort is measured as
} 
based on the traditional chi-square test (p-values $>0.05$ ) and other standard fit measures, including the Comparative Fit Index (CFI above the generally accepted minimum value of 0.95), Root Mean Square Error of Approximation (RMSEA below the 0.05 rule of thumb for good fit) (Thompson 2000), and Tucker-Lewis Index (TLI greater than the generally accepted minimum value of 90 percent) (Kline 1998).

Consistent with theory, results in Panel A show Inspections significantly increase participants' Perceived Inspection Risks for higher-risk clients ( $\mathrm{p}=0.001$, Link 1$)$, but not for lower-risk clients ( $\mathrm{p}=0.346$, Link 1). In turn, participants’ Perceived Inspection Risks significantly increase Auditor Effort ( $\mathrm{p}<0.001$, Link 2). The results support the process mechanism predicted in $\mathrm{H} 1$ that the joint effects of inspections and client risk on auditor effort are mediated by auditors' perceived inspection risks. ${ }^{44}$ Also consistent with theory, results in Panel B show that in addition to increasing auditor effort, participants' Perceived Inspection Risks for higher-risk clients significantly increase their Task-Related Anxiety $(\mathrm{p}=0.002$, Link 2). In turn, participants' Task-Related Anxiety significantly increases Auditors' Low-Quality Decisions $(\mathrm{p}=0.030$, Link 3). The results support the process mechanism predicted in $\mathrm{H} 2$ that the joint effects of risk-based inspections and client risk on auditors' decision performance are mediated by auditors' perceived inspection risks and task-related anxiety. Further, results support full mediation as the effect of Inspections on Auditors' Low-Quality Decisions for lower-risk client is no longer significant in the mediation model (Link 3).

average auditor effort for the 20 periods and Auditors' Low-Quality Decisions is measured as the number of high reports after receiving a low-value signal as a percentage of low-value signals over the 20 periods.

${ }^{44}$ Results support partial mediation as the effect of Inspections on Auditor Effort for higher-risk clients is significant in the mediation model (Link 3), but the effect is relatively weaker than when Perceived Inspection Risks is not included in the model (std. coef. $+0.488, \mathrm{z}=6.950, \mathrm{p}<0.001$ ). Process model results for Auditor Effort are inferentially identical if Task-Related Anxiety is included in the model. Consistent with theory, Perceived Inspection Risks for higher-risk clients increases Task-Related Anxiety (std. coef. $+0.265, \mathrm{z}=2.875, \mathrm{p}=0.004$ ), but Perceived Inspection Risks still significantly increases Auditor Effort (std. coef. $+0.495, \mathrm{z}=7.279, \mathrm{p}<0.001$ ) and TaskRelated Anxiety does not significantly affect Auditor Effort (std. coef. +0.094, z = 1.343, p = 0.182). 


\section{Auditors' Low-Quality Decisions and Suboptimal Decision Strategies}

Next, I analyze participants' reporting decision strategies to provide additional support for my underlying theory that task-related anxiety impairs auditors’ decision processing by increasing the use of suboptimal, more heuristics-based, high-risk decision strategies, and to further mitigate other alternate explanations such as strategic gaming behavior and/or intentional misreporting. Participants' reporting decision strategies for lower- and higher-risk clients are coded as optimal if the participant indicates they follow the signal or as suboptimal for any other strategy. ${ }^{45}$ SEM results are included in the Online Appendix (see Figure A1) and show TaskRelated Anxiety increases Suboptimal Reporting Decision Strategies, a binary variable equal to 1 for suboptimal strategies and 0 otherwise, but only for lower-risk clients $(\mathrm{p}=0.006)$ and not for higher-risk clients ( $\mathrm{p}=0.354)$; in turn, Suboptimal Reporting Decision Strategies significantly increases Auditors' Low-Quality Decisions ( $\mathrm{p}<0.001$ ). Further, I find these results only hold in the Inspections condition and not in the No Inspections condition. ${ }^{46}$ Results are consistent with attentional control theory in a dual-paradigm setting that task-related anxiety from inspections impairs decision performance by increasing auditors’ suboptimal decision strategies, but only for lower-risk clients outside the spotlight.

\section{Supplementary Study with Relatively Lower Resource Constraints}

My theory predicts that auditors' perceived inspection risks combined with relatively higher resource pressure lead to the unintended effects on lower-risk clients. Results from a

\footnotetext{
${ }^{45}$ Participants' reporting decision strategies were collected during the PEQ in open-question format. An independent coder and I, blind to the conditions, separately coded the strategies. Inter-rate reliability was 0.91 and differences were easily resolved. A few participants indicate that they always reported "low" in order to avoid the risk of incurring an incorrect high report. While this decision strategy is suboptimal relative to following the signal, it is not necessarily a low-quality strategy (i.e., it is a conservative strategy). Results are inferentially identical if this decision strategy is coded as suboptimal or optimal.

${ }^{46}$ Specifically, in the No Inspections condition, the effect of Task-Related Anxiety on Suboptimal Reporting Decision Strategies for lower-risk client is not significant (std. coef. $=0.144, \mathrm{z}=1.005$, two-tailed $\mathrm{p}=0.315$ ); whereas, the effect is significant in the Inspections condition (std. coef. $=0.402, \mathrm{z}=3.110$, one-tailed p $=0.001$ ).
} 
second, preliminary study with 42 participants provide some additional evidence for this theory. The experimental method is identical to the previous preliminary study, with the exception that the maximum total effort was increased to 7. In this setting with relatively lower resource constraints, I find risk-based inspections no longer increase auditor effort more for higher- than lower-risk clients and they no longer impair auditors’ decision performance for lower-risk clients (see Tables A3 and A4 in the Online Appendix for tabulated results). Results are consistent with theory that it is the combined pressures of inspections and high resource constraints leading to the unintended effects of risk-based inspections on auditor behavior for lower-risk clients.

\section{Robustness Analyses}

To provide additional support for ceteris paribus tests of H2, I conduct robustness tests for assumptions related to the dependent measure, Auditors' Low-Quality Decisions. First, even though the number of low-value assets is held constant across the inspections conditions, I examine and find that the number of low-value signals for lower-risk clients does not differ across the inspections conditions ( $\mathrm{t}_{94}=1.439, \mathrm{p}=0.153$ ), mitigating concerns that participants in the Inspections versus No Inspections condition had more opportunities to make low-quality decisions for lower-risk clients. Second, I examine and find that 39.6 percent of all participants made at least one low-quality decision during the study (i.e., over the 40 client-period observations), mitigating concerns that the Auditors' Low-Quality Decisions results are driven by a small number of participants. Third, even though the measure for low-quality decisions is independent from effort, I examine and find that results of Auditors' Low-Quality Decisions including tests of $\mathrm{H} 2$ and the mediation process model results are robust to controlling for Auditor Effort, albeit slightly weaker. ${ }^{47}$

\footnotetext{
${ }^{47}$ Specifically, when including Auditor Effort as a covariate in the Auditors' Low-Quality Decisions analyses in Table 2, for lower-risk clients, the effect of Inspections on Auditors' Low-Quality Decisions is marginally significant
} 
Finally, I find that all tests of $\mathrm{H}^{48}$ and the mediation process model results for Auditors ' Low-Quality Decisions are robust to controlling for variables that may be correlated with TaskRelated Anxiety and Auditors' Low-Quality Decisions including participants' (a) cumulative earnings, (b) prior success rate with undetected incorrect high reports after receiving a low-value signal, and (c) bankruptcy position.

\section{CONCLUSIONS AND FUTURE DIRECTIONS}

My study provides theory and experimental evidence on potential unintended effects of risk-based inspections on auditor behavior in a multi-client setting, including disproportionate benefits in terms of auditor effort for higher-risk clients and disproportionate costs in terms of impaired decision performance for lower-risk clients. The results of my study give credence to concerns raised by academics and regulators about auditors managing their inspection risks (Glover and Prawitt 2013; Glover et al. 2014; Houston and Stefaniak 2013; PCAOB 2013, 2016b) and about unintended effects of penalty-based, regulatory inspections (Peecher et al. 2013; Dowling et al. 2015). Interestingly, my finding that risk-based inspections increase instances of auditors' low-quality decisions for lower-risk clients suggests inspections potentially increase instances of non-compliance with regulatory auditing standards for some clients, which contradicts the purpose of regulatory inspections.

My theory-consistent evidence on the factors underlying these potential unintended effects of inspections on auditor behavior is critical for identifying mitigating mechanisms. My study’s design allows for identifying the role of auditors’ perceived inspection risks and taskrelated anxiety in contributing to these unintended effects, which is difficult to disentangle from

(est. $=0.042, \mathrm{t}_{256}=1.428$, one-tailed $\mathrm{p}=0.077$ ), and within the Inspections condition, the effect of Client Risk on Auditors' Low-Quality Decisions is marginally significant (est. $=0.030, \mathrm{t}_{1,318}=1.432$, one-tailed p $=0.076$ ). Process mediation model results of Auditors' Low-Quality Decisions in Panel B of Figure 2 remain inferentially identical when including Auditor Effort as a covariate on Auditors' Low-Quality Decisions.

${ }^{48}$ See results in Table A8, Panels A and B, in the Online Appendix. 
economics-based effects in the real-world. As such, I encourage future research to examine ways to mitigate auditors' perceived inspection risks and related task-related anxiety. For example, future studies could identify changes to the inspections process and outcomes that may reduce auditors' perceived inspection risks and task-related anxiety, while still maintaining the important benefits of the accountability mechanism on overall audit quality (e.g., incorporating rewards for positive inspection results; reducing economic costs, as well as, perceived social and reputational costs associated with inspection deficiencies).

The results of my study also highlight a potential limitation of audit regulators’ riskbased approach such that they fail to incorporate any strategic risks of auditor behavior. Consistent with prior research that finds more undetected misstatements among lower-risk accounts resulting from strategic manager behavior in a risk-based auditing setting (Bowlin 2011), I find more undetected misstatements among lower-risk clients under risk-based inspections. Future research could examine whether incorporating a random selection to riskbased inspections, as currently being considered by the PCAOB, mitigates this potential unintended effect. Furthermore, future research could examine the effects if inspectors behave strategically, as prior research suggests they might (Bowlin 2011). That is, how might auditor behavior in my study change if the assumption that inspection risks are based entirely on preaudit RMM were relaxed? Indeed, the PCAOB does consider some non-pre-audit RMM factors when selecting inspections (e.g., auditor partner and inspection history). For example, if auditors perceive inspection risks to be greater for clients that pose relatively lower pre-audit RMM (i.e., due to strategic behavior by inspectors), might auditors respond by increasing effort to lower preaudit RMM clients thereby increasing opportunities for material misstatements to higher preaudit RMM clients? 
My study is subject to a number of limitations that provide opportunities for future research. I use an abstract setting that includes a number of assumptions and design choices that may differ from natural auditing environments. First, auditor effort is costly but it does not capture cognitive effort and total auditor effort resources are highly constrained. Future research could examine the effects of risk-based inspections in a more natural auditing setting that captures cognitive effort and also further examine whether relaxing the effort resource constraints mitigates the unintended effects by reducing auditors' perceived inspection risks and task-related anxiety. Second, inspections include design choices that could differ from the auditing practice: relatively high predictability rates for inspection selections; relatively low economic penalties for inspection deficiencies; penalties for all effort levels below the maximum effort level; and, relatively weak social consequences of inspection deficiencies. Likewise, assumptions in my setting could differ from the auditing practice as it relates to auditor effort (e.g., the optimal levels of effort), the selection of inspections (e.g., based entirely on pre-audit RMM), the quality of the signals (e.g., the probabilities of audit procedures failing to detect material misstatements), and report outcomes (e.g., the costs associated with failing to report material misstatements given low- versus high-value signals). Future research could examine whether results of my study are robust to these design choices and assumptions.

Finally, my experimental setting does not incorporate all aspects of natural auditing environments. For example, I computerize clients', investors', and regulators' decisions to better isolate the effects of inspections on auditor behavior. Future research could incorporate these aspects to examine whether strategic interactions with managers and/or regulators and whether reputational effects impact results. As another example, I use a relatively stark and coarse measure of auditors' impaired decision performance. Future research can examine effects of risk- 
based inspections on auditors' decision performance in more context rich settings. Despite these limitations, I believe that my setting, which incorporates the key concepts and incentives present in natural auditing environments, allows for my theory to generalize to the auditing practice.

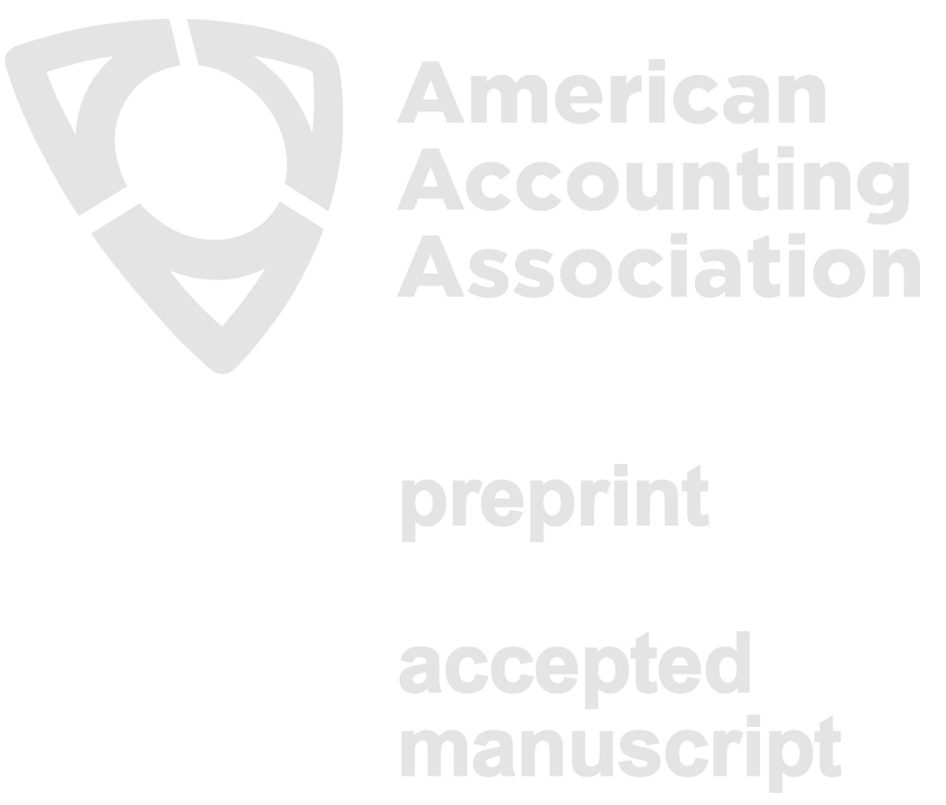




\section{REFERENCES}

Abbott, L. J., K. A. Gunny, and T. C. Zhang. 2013. When the PCAOB talks, who listens? Evidence from stakeholder reaction to GAAP-deficient PCAOB inspection reports of small auditors. Auditing: A Journal of Practice \& Theory 32 (2): 1-31.

Adelberg, S., and C. D. Batson. 1978. Accountability and helping: When needs exceed resources. Journal of Personality and Social Psychology 36 (4): 343-350.

Ashton, R. H. 1990. Pressure and performance in accounting decision settings: Paradoxical effects of incentives, feedback, and justification. Journal of Accounting Research 28: 148-180.

Bedard, J., D. Deis, M. Curtis, and J. G. Jenkins. 2008. Risk monitoring and control in audit firms: A research synthesis. Auditing: A Journal of Practice \& Theory 27 (1): 187-218.

Bowlin, K. O. 2011. Risk-based auditing, strategic prompts, and auditor sensitivity to the strategic risk of fraud. The Accounting Review 86 (4): 1231-1253.

Bowlin, K. O., J. L. Hobson, and M. D. Piercey. 2015. The effects of auditor rotation, professional skepticism, and interactions with managers on audit quality. The Accounting Review 90 (4): 1363-1393.

Buchheit, S., D. W. Dalton, N. L. Harp, C. Hollingsworth. 2016. An analysis of work-life balance factors and alternative work arrangements within the accounting professor. Accounting Horizons 30 (1): 41-62.

Charness, G., U. Gneezy, and A. Imas. 2013. Experimental methods: Eliciting risk preferences. Journal of Economic Behavior \& Organization 87 (2013): 43-51.

Church, B. K., and L. B. Shefchik. 2012. PCAOB inspections and large accounting firms. Accounting Horizons 26 (March): 43-63.

Cohn, M. 2019. Former KPMG and PCAOB officials convicted for inspection scheme. Accounting Today, March 11. Available at: https://www.accountingtoday.com/news/former-kpmg-and-pcaob-officials-convicted-forinspection-scheme.

Daugherty, B., and W. Tervo. 2010. PCAOB inspections of smaller CPA firms: The perspective of inspected firms. Accounting Horizons 24 (2): 189-219.

Daugherty, B., D. Dickins, and W. Tervo. 2011. Negative PCAOB inspections of triennially inspected auditors and involuntary and voluntary client losses. International Journal of Auditing 15 (3): 231-246. 
DeFond, M. L. 2010. How should the auditors be audited? Comparing the PCAOB inspections with the AICPA peer reviews. Journal of Accounting and Economics 49 (February): 104108.

DeFond, M. L., and C. S. Lennox. 2011. The effect of SOX on small auditor exits and audit quality. Journal of Accounting \& Economics 52 (1): 21-40.

DeFond, M. L., and C. S. Lennox. 2017. Do PCAOB Inspections Improve the Quality of Internal Control Audits? Journal of Accounting Research 55 (3): 591-627.

DeZoort, F.T. and A.T. Lord. 1997. A review and synthesis of pressure effects research in accounting. Journal of Accounting Literature, 16: 28-85.

Dowling, C., W. R. Knechel, and R. Moroney. 2015. Public Oversight of Audit Firms: The Slippery-Slope of Enforcing Regulation. Working paper, University of Melbourne, University of Florida, and Monash University.

Drake, K. D., N. C. Goldman, and S. J. Lusch. 2016. Do income tax-related deficiencies in publicly disclosed PCAOB Part II reports influence audit client financial reporting of income tax accounts? The Accounting Review 91 (5): 1411-1439.

Eysenck, M. W., N. Derakshan, R. Santos, and M. G. Calvo. 2007. Anxiety and cognitive performance: Attentional control theory. Emotion 7 (2): 336-353.

Fischbacher, U. 2007. z-Tree. Zurich toolbox for readymade economic experiments. Experimental Economics 10 (2): 171-178.

Fogarty, T. J. 1996. The imagery and reality of peer review in the U.S.: Insights from institutional theory. Accounting, Organizations and Society 21 (2/3): 243-267.

Franzel, J. 2013. “Auditor objectivity and skepticism - What's next?” Center for Audit Quality at the 2013 American Accounting Association (AAA) Annual Conference. Anahiem, CA. 5 August 2013. Expert Panel Discussion available at: http://www.thecaq.org/resources/video-library/caq-at-aaa.

Glover, S. M., and D. F. Prawitt. 2013. Enhancing auditor professional skepticism. Monograph produced by the Standards Working Group of the Global Public Policy Committee. Available at www.thecaq.org/docs/research/skepticismreport.pdf.

Glover, S. M., M. H. Taylor, and Y-J. Wu. 2014. Closing the gap between auditor performance and regulators' expectations when auditing fair value measurements: Evidence from practicing auditors. Working paper, Brigham Young University, and Case Western Reserve University. 
Gramling, A. A., J. Krishnan, and Y. Zhang. 2011. Are PCAOB-identified audit deficiencies associated with a change in reporting decisions of triennially inspected audit firms? Auditing: A Journal of Practice \& Theory 30 (3): 59-79.

Haynes, C. M., and S. J. Kachelmeier. 1998. The effects of accounting contexts on accounting decisions: A synthesis of cognitive and economic perspectives in accounting experimentation. Journal of Accounting Literature 17: 97-136.

Hermanson, D. R., R. W. Houston, and J. C. Rice. 2007. PCAOB inspections of smaller CPA firms: Initial evidence from inspection reports. Accounting Horizons 21 (June): 137-152.

Hilary, G., and C. Lennox. 2005. The credibility of self-regulation: Evidence from the accounting profession's peer review program. Journal of Accounting and Economics 40: 211-229.

Holt, C. and S. Laury. 2002. Risk aversion and incentive effects. American Economic Review (92): 1644-1655.

Houston, R. W., and C. M. Stefaniak. 2013. Audit partner perceptions of post-audit review mechanisms: An examination of internal quality reviews and PCAOB inspections. Accounting Horizons 27 (1): 23-49.

Hutt, J., and G. Weidner. 1993. The effects of task demand and decision latitude on cardiovascular reactivity to stress. Behavioral Medicine 18 (Winter): 181-188.

International Forum of Independent Audit Regulators (IFIAR). 2019. Survey of Inspection Findings 2018. IFIAR report released May 16, 2019. Available at: https://www.ifiar.org/?wpdmdl=9603.

Kachelmeier, S. J., and R. R. King. 2002. Using laboratory experiments to evaluate accounting policy issues. Accounting Horizons 16 (3): 219-233.

Kachelmeier, S. J., T. Majors, and M. G. Williamson. 2014. Does intent modify risk-based auditing? The Accounting Review 89 (6): 2181-2201.

King, R. R. 1991. Using Experimental Economics in Auditing Research. Auditing: Advances in Behavioral Research, edited by L.A. Ponemon and D.R. L. Gabhart. New York: Springer-Verlag, 93-112.

King, R. R. 2002. An experimental investigation of self-serving biases in an auditing trust game: The effect of group affiliation. The Accounting Review 77 (2): 265-284.

Kline, R. B. 1998. Principles and practices of structural equation modeling. New York: Guilford Press. 
Knechel, W. R. 2007. The business risk audit: Origins, obstacles, and opportunities. Accounting, Organizations and Society 32 (4-5): 383-408.

Knechel, W. R., G. V. Krishnan, M. Pevzner, L. B. Shefchik, and U. K. Velury. 2013. Audit quality: Insights from the academic literature. Auditing: A Journal of Practice \& Theory 32 (Special Issues): 385-421.

Krishnan, J., J. Krishnan, and H. Song. 2017. PCAOB international inspections and audit quality. The Accounting Review 92 (5): 143-166.

Lamoreaux, P. 2017. Does PCAOB inspection access affect audit quality? An examination of foreign firms listed in the United States. Journal of Accounting and Econonomics 61:31337.

Lerner, J., and P. Tetlock. 1999. Accounting for the effects of accountability. Psychological Bulletin (March): 255-275.

Libby, R., R. Bloomfield, and M. Nelson. 2002. Experimental research in financial accounting. Accounting, Organizations and Society 27: 775-810.

Lopez, D. M., and G. F. Peters. 2012. The effects of workload compression on audit quality. Auditing: A Journal of Practice \& Theory 31 (November): 139-165.

Michaels, D., and M. Rapoport. 2017. KPMG fires partners over leak of audit regulator's confidential plan. The Wall Street Journal, April 11.

Peecher, M. E., I. Solomon, K. T. Trotman. 2013. An accountability framework for financial statement auditors and related research questions. Accounting, Organizations and Society 38 (8): 596-620.

Public Companies Accounting Oversight Board (PCAOB). 2003. Rules on investigations and adjudications. PCAOB Release No. 2003-015. Washington, D.C.: PCAOB.

Public Companies Accounting Oversight Board (PCAOB). 2008. Report on the PCAOB's 2004, 2005, 2006, and 2007 Inspections of Domestic Annually Inspected Firms. Washington, DC.: PCAOB.

Public Company Accounting Oversight Board (PCAOB). 2013. Keynote address by Jay D. Hanson, Board Member, at Baruch College $12^{\text {th }}$ Annual Financial Reporting Conference. Available at: http://pcaobus.org/News/Speech/Pages/05022013_Hanson.aspx.

Public Company Accounting Oversight Board (PCAOB). 2016a. Staff Inspection Brief: Information about 2016 Inspections. Vol. 2016/3. Washington, D.C.: PCAOB. Available at: https://pcaobus.org/Inspections/Documents/Inspection-Brief-2016-3-Issuers.pdf. 
Public Company Accounting Oversight Board (PCAOB). 2016b. Keynote address by Jeanette Franzel, Board Member, at Baruch College $15^{\text {th }}$ Annual Financial Reporting Conference. Available at: https://pcaobus.org/News/Speech/Pages/Franzel-progress-in-auditoversight-Baruch-5-5-16.aspx.

Public Company Accounting Oversight Board (PCAOB). 2017. Staff Inspection Brief: Information about 2017 Inspections. Vol. 2017/3. Washington, D.C.: PCAOB. Available at: https://pcaobus.org/Inspections/Documents/inspection-brief-2017-3-issuer-scope.pdf.

Public Company Accounting Oversight Board (PCAOB). 2018. Keynote address by William D. Duhnke, Chairman, at the 2018 Deloitte/University of Kansas Auditing Symposium, Lawrence, Kansas, "PCAOB Transitions for the Future” available at https://pcaobus.org/News/Speech/Pages/PCAOB-Transition.aspx.

Public Company Accounting Oversight Board (PCAOB). 2019. Staff Inspection Brief: Staff Preview of 2018 Inspection Observations. May 6, 2019. Washington, D.C.: PCAOB. Available at https://pcaobus.org/Inspections/Documents/Staff-Preview-2018-InspectionObservations.pdf.

Schatzberg, J. W., and G. R. Sevcik. 1994. A multiperiod model and experimental evidence of independence and “lowballing.” Contemporary Auditing Research 11 (Summer): 137174.

Stefaniak, C. M., R. W. Houston, and D. M. Brandon. 2017. Investigating inspection risk: An analysis of PCAOB inspections and internal quality reviews. Auditing: A Journal of Practice \& Theory 36 (1): 151-168.

Stone, D. N., and K. Kadous. 1997. The joint effect of task-related negative affect and task difficulty in multiattribute choice. Organization Behavior and Human Decision Processes 70 (May): 159-174.

Thompson, B. “Ten commandments of structural equation modeling.” In Reading and Understanding More Multivariate Statistics, edited by Grimm L. G., and P. R. Yarnold, 2000, 261-284. Washington DC: American Psychological Association.

Verbeke, G. 1997. Linear Mixed Models for Longitudinal Data. In: Linear Mixed Models in Practice. Lecture Notes in Statistics, Vol. 126. Springer, New York, NY

Whitehouse, T. 2019. Former KPMG, PCAOB leader gets prison time in inspections scandal. Compliance Week, August 12. Available at: https://www.complianceweek.com/accounting-and-auditing/former-kpmg-pcaob-leadergets-prison-time-in-inspections-scandal/27554.article.

Winn, A. 2019. Partner rotation and PCAOB Inspections: Effects on Auditor Effort. Working paper, Portland State University. 
Yerkes, R. M., and J. D. Dodson. 1908. The relation of strength and stimulus to rapidity of habit formation. Journal of Comparative Neurology and Psychology 459-82.
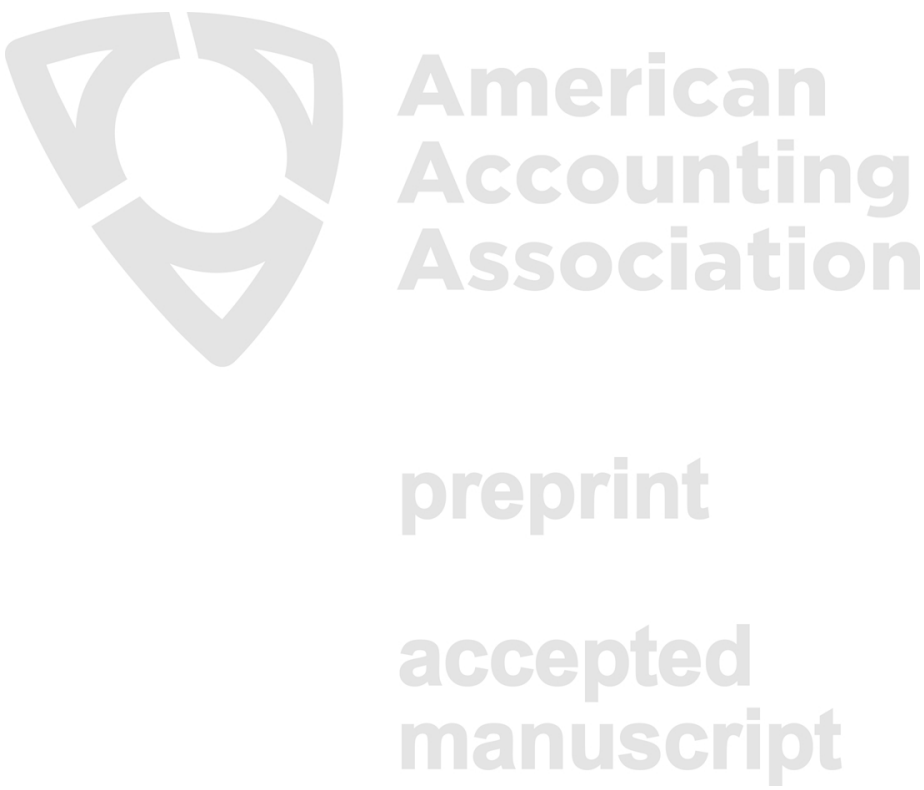
Appendix A

[insert link to Online Appendix here]

\section{American Accounting Association}

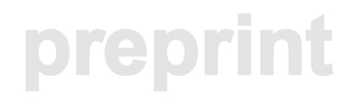

accepted manuscript 


\section{Appendix B}

Panel A: Flowchart of Participants' Decisions in the Experimental Steps
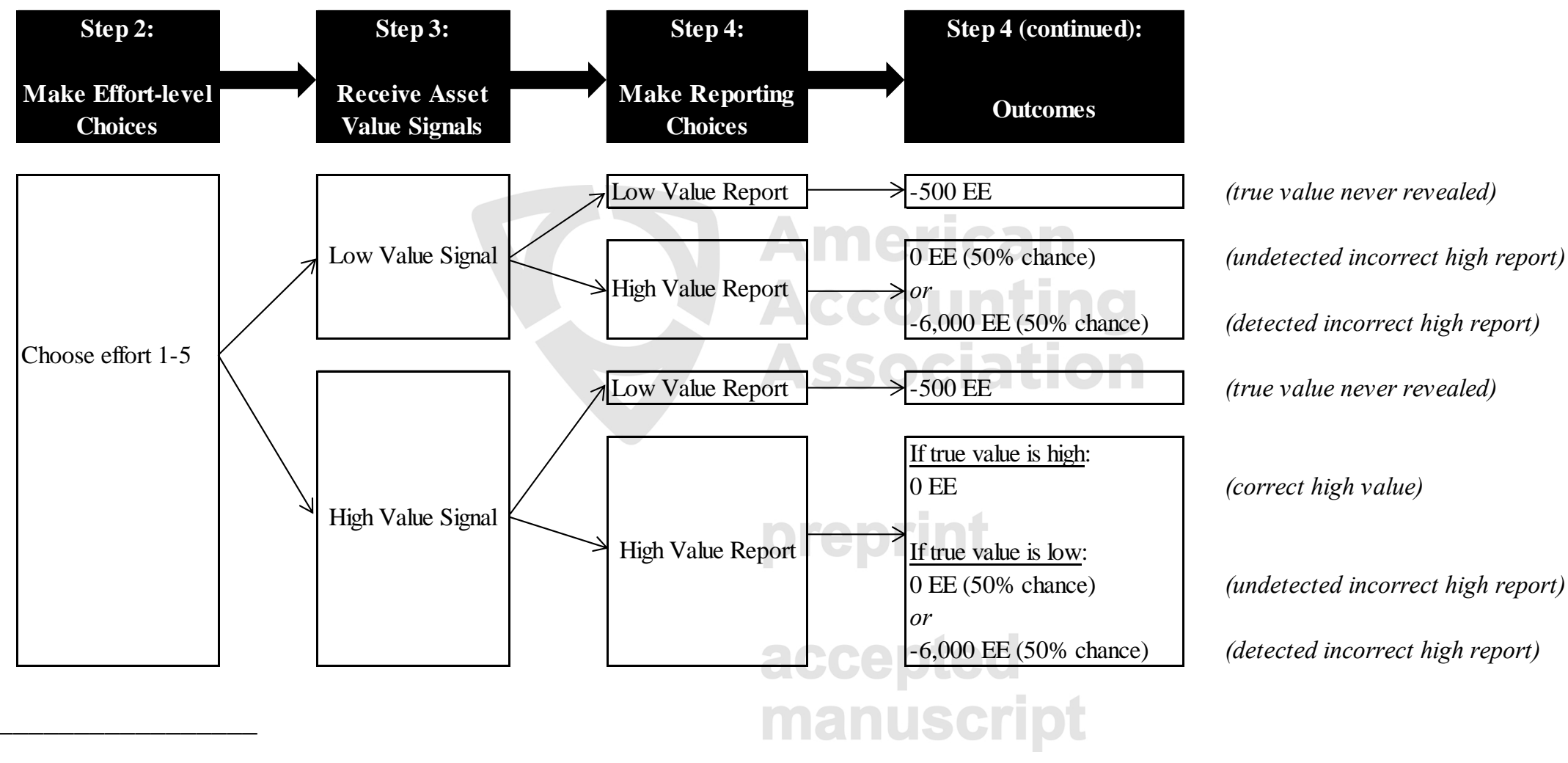

Panel A displays a flowchart of the participants' decisions in experimental steps 2 through 4. Included are the possible decisions participants can make (e.g., effort-level choices and reporting choices) and the corresponding outcomes. The probabilities and expected outcomes for each potential outcome are detailed in Panels B and C. The experimental steps outlined above are the same for higher-risk and lower-risk clients and do not differ across the inspections conditions. 


\section{Panel B: Flowchart of Expected Costs for Report Decisions for Lower-Risk Clients}
A. Signal of asset value
B. Knowledge about the signal
C. Report options /
D. Expected costs of report
E.
Probability of Outcome based on Report
F. Report Outcome
Probability of Cost of Outcome
H. Cost of Outcome

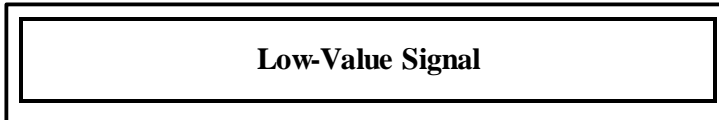

The probability the signal is incorrect is $10 \%$

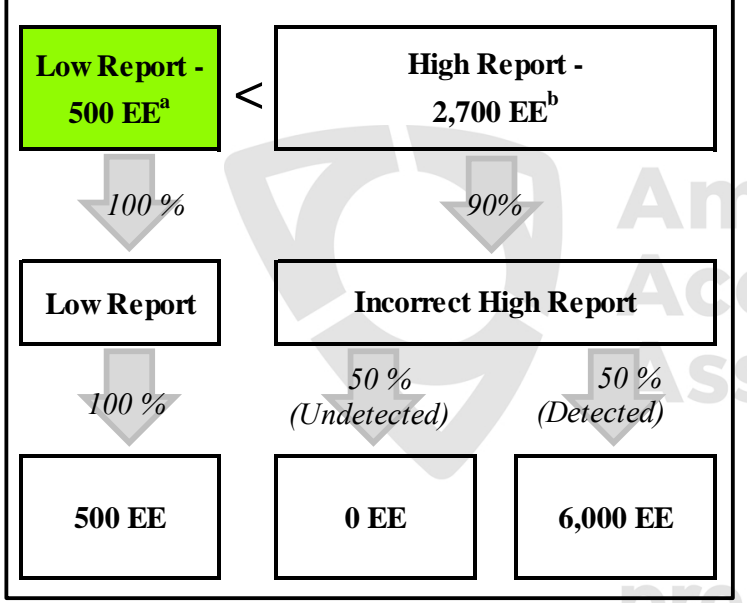

High-Value Signal

If the asset value is low, the probability the signal is incorrect is equal to the "error rate"

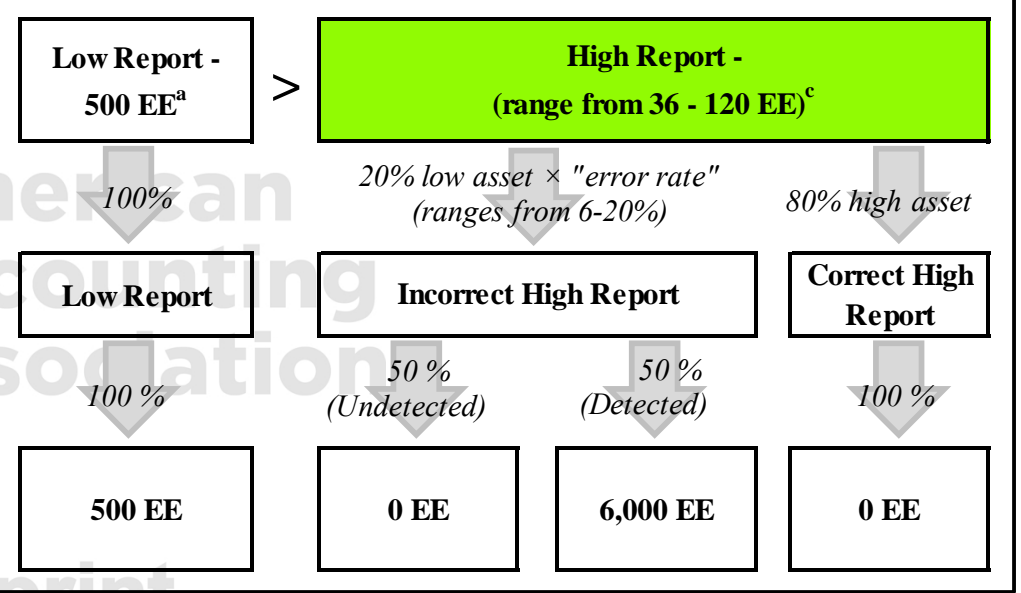

Panel B displays a flowchart of the expected costs and report decisions for lower-risk clients following each type of signal. The boxes highlighted in green represent the wealth-maximizing report decisions following the respective signals, which are to follow the signal.

a. The cost of reporting a low value is always $500 \mathrm{EE}$ regardless of the actual value of the asset.

b. A "low-value signal" is $90 \%$ accurate. If a participant reports a high value after receiving a "low-value signal," there is a $90 \%$ chance the value is low and a $50 \%$ chance that an incorrect high report will be detected and charged a cost of 6,000 EE; therefore, the expected value is $2,700 \mathrm{EE}(0.9 \times 0.5 \times 6,000 \mathrm{EE})$.

c. If the true value of the asset is low, the signal error rate depends on the effort-level choice. The signal error rate for a low asset ranges from $20 \%$ for an effortlevel choice of "1" to $6 \%$ for an effort-level choice of "5." The expected cost of issuing a high report after receiving a high-value signal is always less than the cost of issuing a low report (i.e., $500 \mathrm{EE}$ ). The expected cost is calculated as follows: $20 \%$ chance of being a low asset $\times$ the error rate of the signal $\times 50 \%$ chance of detecting an incorrect high report $\times 6,000 \mathrm{EE}$ cost of an incorrect high report. Therefore, the expected cost ranges from 36 to $120 \mathrm{EE}$. 


\section{Panel C: Flowchart of Expected Costs for Report Decisions for Higher-Risk Clients}

\begin{tabular}{|c|c|}
\hline A. & Signal of asset value \\
\hline B. & Knowledge about the signal \\
\hline C. & Report options / \\
\hline D. & Expected costs of report \\
\hline E. & $\begin{array}{c}\text { Probability of Outcome } \\
\text { based on Report }\end{array}$ \\
\hline F. & Report Outcome \\
\hline G. & $\begin{array}{c}\text { Probability of Cost of } \\
\text { Outcome }\end{array}$ \\
\hline H. & Cost of Outcome \\
\hline
\end{tabular}

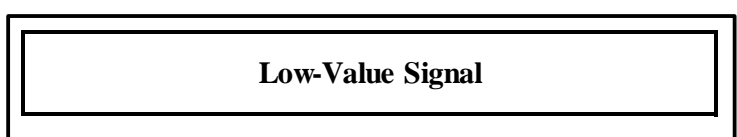

The probability the signal is incorrect is $10 \%$

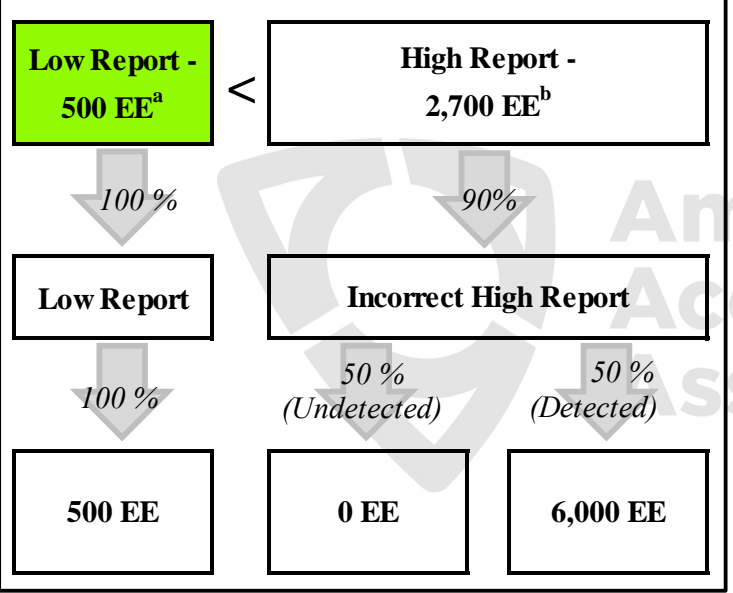

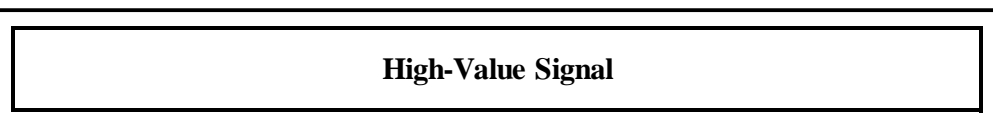

If the asset value is low, the probability the signal is incorrect is equal to the "error rate"

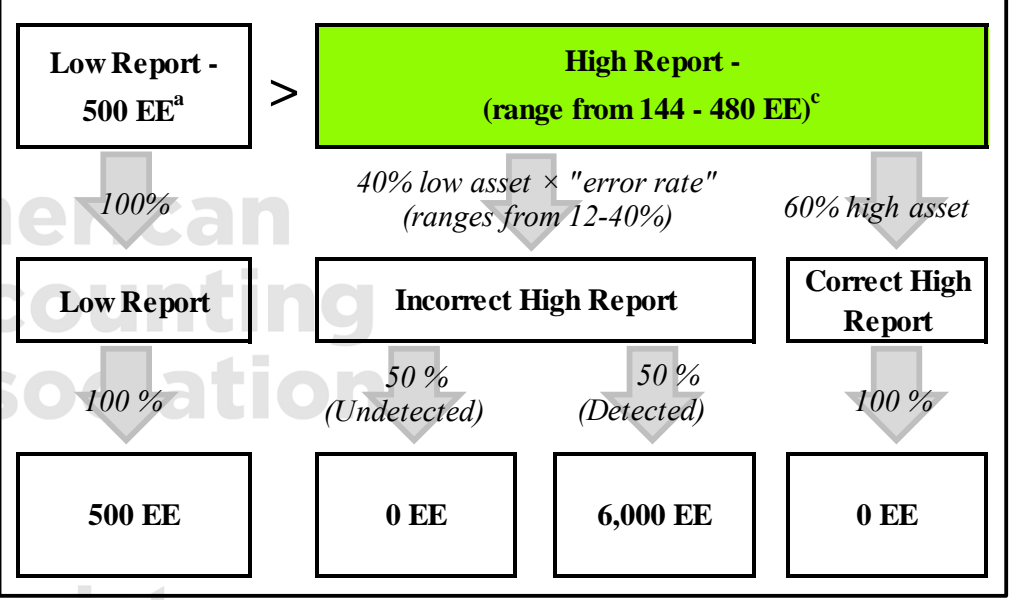

Panel C displays a flowchart of the expected costs and report decisions for higher-risk clients following each type of signal. The boxes highlighted in green represent the wealth-maximizing report decisions following the respective signals, which are to follow the signal.

Notes: The boxes highlighted in green represent the wealth-maximizing report choices following the respective signals, which are to follow the signal.

a. The cost of reporting a low value is always $500 \mathrm{EE}$ regardless of the actual value of the asset.

b. A "low-value signal" is $90 \%$ accurate. If a participant reports a high value after receiving a "low-value signal," there is a $90 \%$ chance the value is low and a $50 \%$ chance that an incorrect high report will be detected and charged a cost of 6,000 EE; therefore, the expected value is 2,700 EE $(0.9 \times 0.5 \times 6,000 \mathrm{EE})$.

c. If the true value of the asset is low, the signal error rate depends on the effort-level choice. The signal error rate for a low asset ranges from $40 \%$ for an effortlevel choice of " 1 " to $12 \%$ for an effort-level choice of "6." The expected cost of issuing a high report after receiving a high-value signal is always less than the cost of issuing a low report (i.e., $500 \mathrm{EE}$ ). The expected cost is calculated as follows: $20 \%$ chance of being a low asset $\times$ the error rate of the signal $\times 50 \%$ chance of detecting an incorrect high report $\times 6,000 \mathrm{EE}$ cost of an incorrect high report. Therefore, the expected cost ranges from 144 to $480 \mathrm{EE}$. 


\section{Exhibit 1 \\ Experimental Design Choices}

Panel A: Cost of Effort and Signal Error Rates for Effort-Level Choices

\begin{tabular}{|c|c|c|c|}
\hline \multirow{2}{*}{$\begin{array}{c}\text { Effort- } \\
\text { Level } \\
\text { Choice }\end{array}$} & \multirow{2}{*}{$\begin{array}{c}\text { Total Cost of } \\
\text { Effort }\end{array}$} & $\begin{array}{c}\text { Signal Error Rate - True Asset Value is } \\
\text { “Low" but Signal says “High” }\end{array}$ \\
\cline { 3 - 4 } & & Type A Assets & Type B Assets \\
\hline 1 & 350 & $20 \%$ & $40 \%$ \\
\hline 2 & 375 & $16 \%$ & $28 \%$ \\
\hline 3 & 400 & $8 \%$ & $16 \%$ \\
\hline 4 & 450 & $7 \%$ & $14 \%$ \\
\hline 5 & 500 & $6 \%$ & $12 \%$ \\
\hline
\end{tabular}

Panel B: Review Penalties for Effort-Level Choices

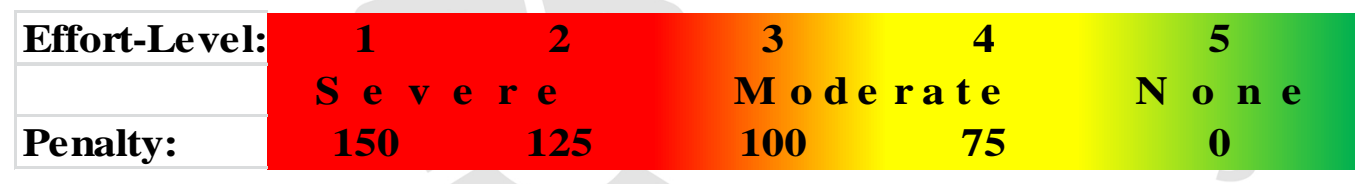

Panel A displays the table provided to participants in the experimental instructions to summarize the cost of effort and the related signal error rates for each effort-level choice. Panel B displays the table provided to participants in the Inspections condition to summarize the review penalties associated with each effort-level choice. 
Figure 1

Summary of Results

Panel A: Effects of Inspections and Client Risk on Auditor Effort
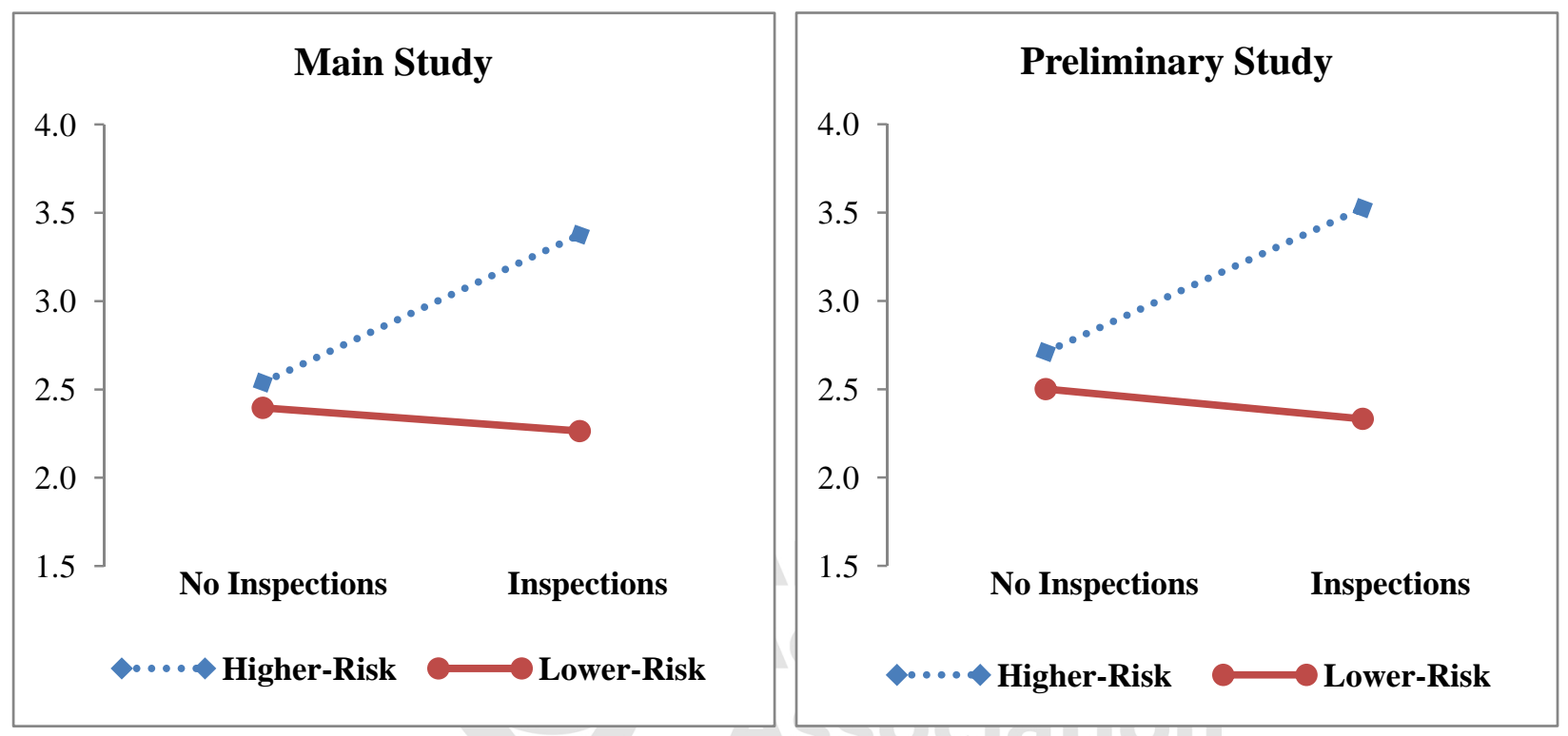

Panel B: Effects of Inspections and Client Risk on Auditors' Low-Quality Decisions
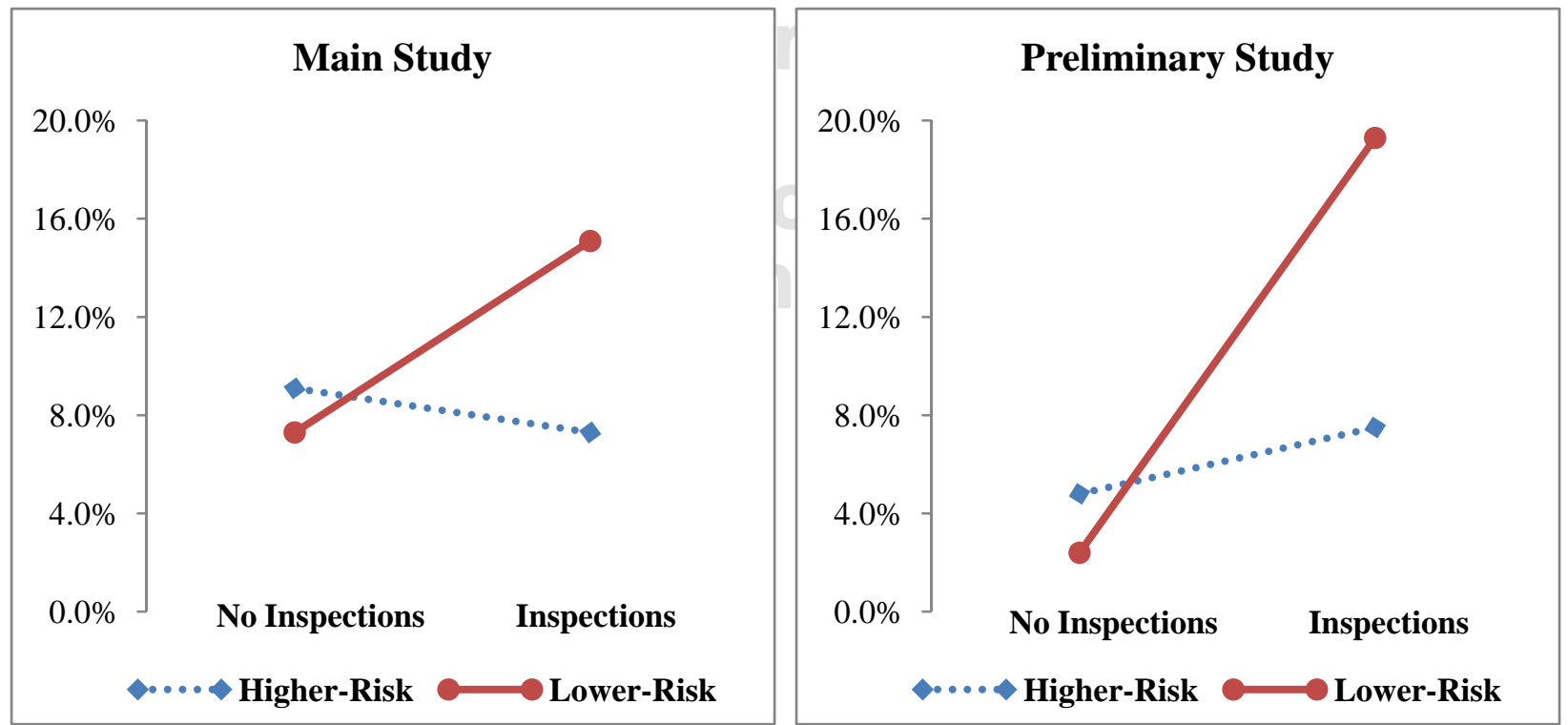

Figure 1 displays the mean dependent measures by experimental condition for the main and preliminary studies. Means in the main study are adjusted for Period and Session. Means in the preliminary study are adjusted for Period. Mean Auditor Effort displayed in Panel A is calculated as participants' average effort-level choice, ranging from 1 to 5 for each client, subject to a constraint that total effort does not exceed 6, over 20 repeated periods $(\mathrm{n}=$ 
3,840 client-period observations for 96 participants in the main study and $n=1,760$ client-period observations for 44 participants in the preliminary study). Mean Auditors' Low-Quality Decisions displayed in Panel B is calculated as participants' cumulative number of low-quality decisions, a binary variable equal to 1 if the participant reports high after receiving a low-value signal, and 0 otherwise, as a percentage of low-value signals $(n=1,325$ client-period observations with low-value signals for the main study and $n=618$ client-period observations with low-value signals for the preliminary study). Inspections is manipulated between-participants, such that participants in the Inspections condition are subject to an inspections regime modeled after the PCAOB's risk-based inspections process and participants in the No Inspections condition are not subject to an inspections regime. Client Risk is manipulated within participants, such that higher-risk (lower-risk) clients have a relatively higher (lower) probability of containing a misstatement in the financial statements.
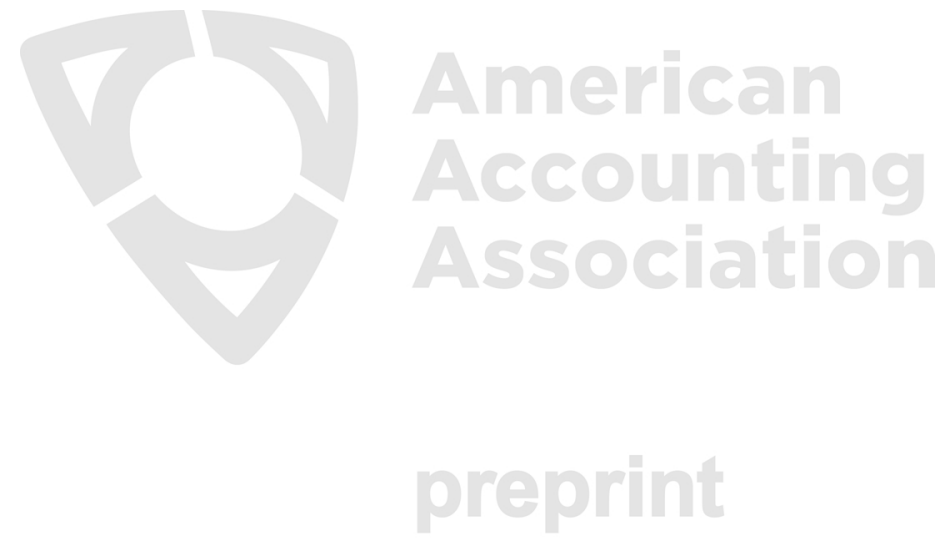
Figure 2

Mediation Process Model Results

\section{Panel A: Auditor Effort}

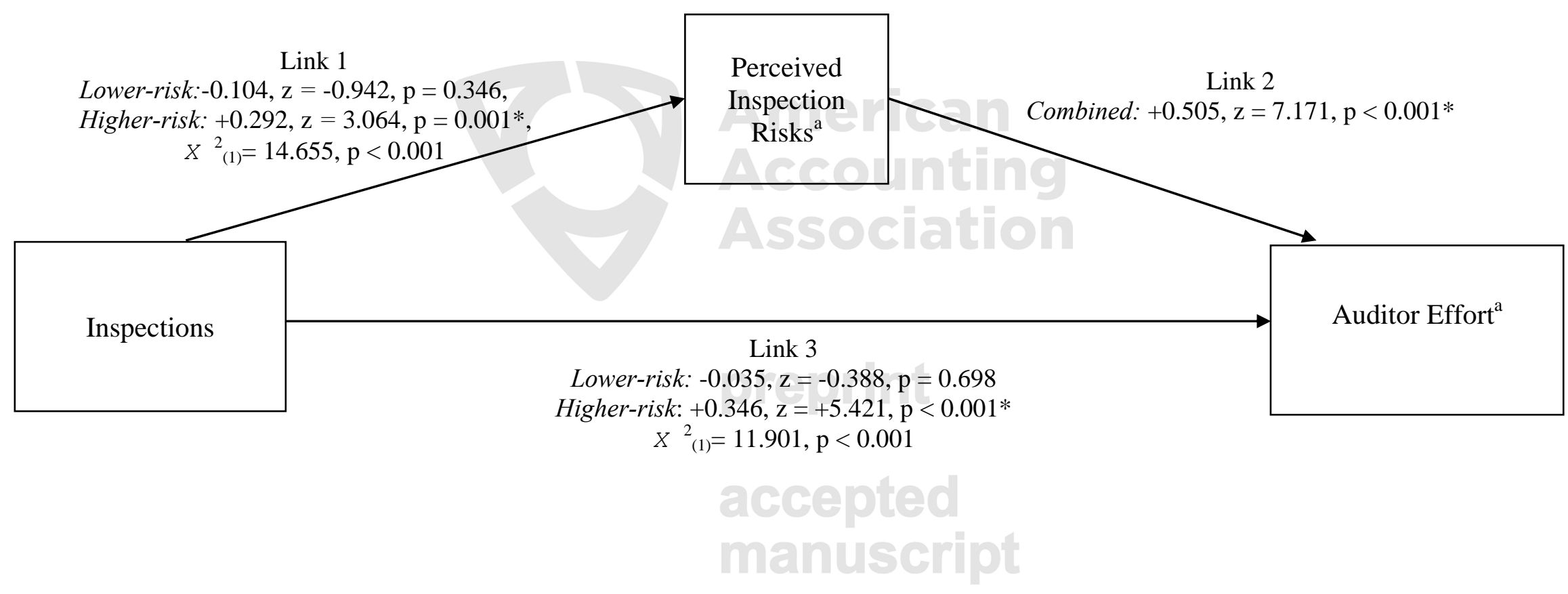




\section{Panel B: Auditors' Low-Quality Decisions}

Link 2

Lower-risk:-0.052, $\mathrm{z}=-0.523$,

Link 1

Lower-risk: $-0.104, \mathrm{z}=-0.942$, $\mathrm{p}=0.346$,

Higher-risk: $+0.292, \mathrm{z}=3.064$,

$\mathrm{p}=0.001^{*}$

$x_{(1)}^{2}=14.655, p$

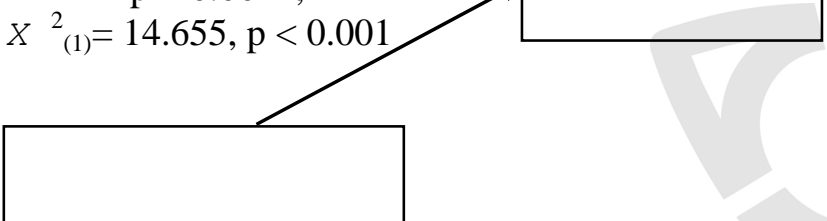

Perceived

Inspection

$\mathrm{p}=0.601$,

Higher-risk: $+0.265, \mathrm{z}=2.875$,

$=0.002 *$

Inspections

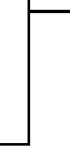

Link 4

Lower-risk: $+0.116, \mathrm{z}=1.162, \mathrm{p}=0.123 *$

Higher-risk: $-0.077, \mathrm{z}=-0.797, \mathrm{p}=0.426$

$$
X_{(1)}^{2}=3.892, \mathrm{p}=0.049
$$

Figure 2 displays the mediation process model results of Inspections and Client Risk on Auditor Effort (Panel A) and on Auditors' Low-Quality Decisions (Panel B) using structural equation modeling in Stata. The path analyses simultaneously test the relationships among the variables. The number of observations is 192 with two groups for Client Risk (higher- and lower-risk clients). The models include clustered robust standard errors for participants $(\mathrm{n}=96)$ to control for the lack of independence in participants' repeated observations and also include standardized path coefficients. The independent variables (Inspections and Client Risk) and dependent measures (Auditor Effort and Auditors' Low-Quality Decisions) are described in the notes of Figure 1. The mediation measures (Perceived Inspection Risks and Task-Related Anxiety) are described in the notes of Table 3. The model in Panel A for Auditor Effort has good fit with a Chi-square $=0.973$, $\mathrm{df}=3, \mathrm{p}=0.808$; Root mean squared error of approximation $(\mathrm{RMSEA})=0.000$; Comparative fit index $(\mathrm{CFI})=1.000$; and Tucker-Lewis index $(\mathrm{TLI})=1.072$. The model in Panel B for Auditors' Low-Quality Decisions also has good fit with a Chi-square = 5.392, $\mathrm{df}=8, \mathrm{p}=0.715$; RMSEA = 0.000; CFI = 1.000; and TLI $=1.143 .{ }^{*}$ One-tailed p-value for directional predictions. All other p-values are two-tailed.

a. Adjusted for Session, a significant covariate. In Panel A, the effect of Session is significant on auditors' Perceived Inspection Risks (std. coef. +0.224 , $\mathrm{z}=$ 2.573, $\mathrm{p}=0.010$ ) and is not significant on Auditor Effort (std. coef. $-0.033, \mathrm{z}=0.577, \mathrm{p}=0.564$ ). In Panel B, the effect of Session is significant on auditors' Perceived Inspection Risk (std. coef. $+0.224, \mathrm{z}=2.573, \mathrm{p}=0.010$ ), is significant on auditors' Task-Related Anxiety (std. coef. $+0.280, \mathrm{z}=2.964, \mathrm{p}=0.003$ ), and is not significant on Auditors' Low-Quality Decisions (std. coef. $+0.123, \mathrm{z}=1.571, \mathrm{p}=0.116$ ). 
Table 1

Results of Auditor Effort

Panel A: Means (Standard Deviation)

\begin{tabular}{|c|c|c|c|}
\hline $\begin{array}{l}\text { Inspection } \\
\text { Regime } \\
\end{array}$ & $\frac{\text { Lower- }}{\underline{\text { Risk }}}$ & $\frac{\text { Higher- }}{\underline{\text { Risk }}}$ & Total \\
\hline No Inspection & $\begin{array}{c}2.397 \\
(0.889) \\
n=980\end{array}$ & $\begin{array}{c}2.539 \\
(1.006) \\
n=980\end{array}$ & $\begin{array}{c}4.825 \\
(1.516) \\
n=980\end{array}$ \\
\hline Inspection & $\begin{array}{c}2.265 \\
(0.845) \\
n=940\end{array}$ & $\begin{array}{c}3.377 \\
(0.905) \\
n=940\end{array}$ & $\begin{array}{c}5.609 \\
(1.009) \\
n=940\end{array}$ \\
\hline Average & $\begin{array}{c}2.331 \\
(0.871) \\
n=1,920\end{array}$ & $\begin{array}{c}2.958 \\
(1.036) \\
n=1,920\end{array}$ & \\
\hline
\end{tabular}

Panel B: Linear Mixed-Effects Regression Model

\begin{tabular}{|c|c|c|c|c|c|}
\hline DV = Auditor Effort & Est. & Std. Error & df & t-stat. & p-value \\
\hline Intercept & 3.238 & 0.179 & 97.72 & 18.092 & $<0.001$ \\
\hline Inspections & 0.838 & 0.123 & 104.97 & 6.795 & $<0.001$ \\
\hline Client Risk & 1.112 & 0.035 & $2,564.96$ & 31.459 & $<0.001$ \\
\hline Inspections $\times$ Client Risk & 0.970 & 0.049 & $2,557.05$ & 19.614 & $<0.001$ \\
\hline Period & 0.001 & 0.002 & $1,485.16$ & 0.370 & 0.711 \\
\hline Session & 0.099 & 0.119 & 91.52 & 0.833 & 0.407 \\
\hline
\end{tabular}

\section{Panel C: Follow-up Planned Contrasts}

\begin{tabular}{|c|c|c|c|c|c|}
\hline DV = Auditor Effort & $\begin{array}{c}\text { Mean } \\
\text { Diff. }\end{array}$ & $\begin{array}{l}\text { Std. } \\
\text { Error }\end{array}$ & df & F-stat. & p-value \\
\hline $\begin{array}{l}\text { Lower-Risk Clients: } \\
\text { No Inspection = Inspection }\end{array}$ & -0.132 & 0.120 & $1,95.37$ & 1.220 & 0.272 \\
\hline $\begin{array}{l}\text { Higher-Risk Clients: } \\
\text { No Inspection < Inspection }\end{array}$ & 0.838 & 0.123 & $1,104.97$ & 46.173 & $<0.001^{*}$ \\
\hline
\end{tabular}

Table 1 presents results of auditor effort. The independent variables (Inspections and Client Risk) and dependent measures (Auditor Effort) are described in the notes of Figure 1. Panel A presents descriptive statistics for Auditor Effort including condition means, standard deviations, and the number of client-period observations. The means are adjusted for Period and Session. Panel B presents results of a linear mixed-effects regression model to test the joint effects of Inspections and Client Risk on Auditor Effort. The model includes a random intercept for each participant and Client Risk and Period as repeated variables to adjust for the correlation of repeated observations for each 
participant (two clients over 20 periods). Panel C presents results of follow-up planned contrasts from the linear mixed-effects regression model. *One-tailed p-value for directional predictions. All other p-values are two-tailed.
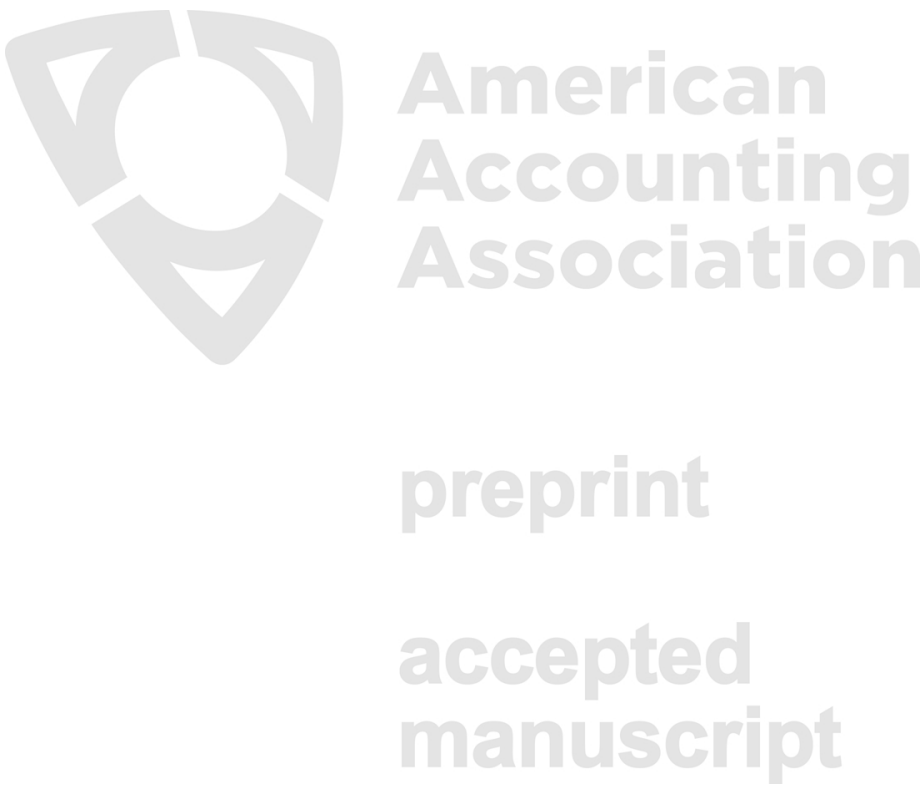
Table 2

Results of Auditors' Low-Quality Decisions

\begin{tabular}{|c|c|c|c|}
\hline \multicolumn{4}{|c|}{ Panel A: Means (Standard Deviation) } \\
\hline \multirow[b]{2}{*}{$\begin{array}{l}\text { Inspection } \\
\text { Regime } \\
\end{array}$} & \multicolumn{3}{|c|}{ Client Risk } \\
\hline & $\begin{array}{c}\text { Lower- } \\
\text { Risk }\end{array}$ & $\frac{\text { Higher- }}{\text { Risk }}$ & Average \\
\hline No Inspection & $\begin{array}{c}0.073 \\
(0.284) \\
n=125\end{array}$ & $\begin{array}{c}0.091 \\
(0.304) \\
n=536\end{array}$ & $\begin{array}{c}0.082 \\
(0.300) \\
n=661\end{array}$ \\
\hline Inspection & $\begin{array}{c}0.151 \\
(0.350) \\
n=113\end{array}$ & $\begin{array}{c}0.073 \\
(0.238) \\
n=551\end{array}$ & $\begin{array}{c}0.112 \\
(0.262) \\
n=664\end{array}$ \\
\hline Average & $\begin{array}{c}0.112 \\
(0.318) \\
n=238\end{array}$ & $\begin{array}{c}0.082 \\
(0.273) \\
n=1,087\end{array}$ & \\
\hline
\end{tabular}

Panel B: Generalized Mixed-Effects Logistic Regression Model

\begin{tabular}{|c|c|c|c|c|}
\hline DV = Low-Quality Decisions & Coef. & Std. Error & t-stat. & p-value \\
\hline Intercept & 2.562 & 0.531 & 4.828 & $<0.001$ \\
\hline Inspections & 0.382 & 0.499 & 0.766 & 0.445 \\
\hline Client Risk & 1.201 & 0.349 & 3.444 & 0.001 \\
\hline Inspections $\times$ Client Risk & 1.388 & 0.600 & 2.312 & 0.021 \\
\hline Period & 0.033 & 0.021 & 1.557 & 0.120 \\
\hline Session & 0.801 & 0.456 & 1.755 & 0.083 \\
\hline
\end{tabular}

\section{Panel C: Follow-up Planned Contrasts}

\begin{tabular}{|c|c|c|c|c|c|}
\hline DV = Low-Quality Decisions & Est. & $\begin{array}{l}\text { Std. } \\
\text { Error }\end{array}$ & df & t-stat. & p-value \\
\hline $\begin{array}{l}\text { No Inspections: } \\
\quad \text { Lower-Risk = Higher-Risk }\end{array}$ & 0.008 & 0.020 & 1,319 & 0.402 & 0.688 \\
\hline $\begin{array}{l}\text { Inspections: } \\
\quad \text { Lower-Risk > Higher-Risk }\end{array}$ & -0.070 & 0.031 & 706 & -2.234 & $0.013 *$ \\
\hline $\begin{array}{l}\text { Lower-Risk Clients: } \\
\text { No Inspection < Inspection }\end{array}$ & 0.063 & 0.041 & 246 & 1.531 & $0.064 *$ \\
\hline $\begin{array}{l}\text { Higher-Risk Clients: } \\
\text { No Inspection = Inspection }\end{array}$ & -0.015 & 0.020 & 127 & -0.453 & 0.453 \\
\hline
\end{tabular}

Table 2 presents results of auditors' decision performance. The independent variables (Inspections and Client Risk) and dependent measure (Auditors' Low-Quality Decisions) are described in the notes of Figure 1. Panel A presents 
descriptive statistics for Auditors' Low-Quality Decisions including condition means, standard deviations, and the number of client-period observations (i.e., the number of low-value signals). The means are adjusted for Period and Session. Panel B presents results of a generalized linear mixed-effects logistic regression model to test the joint effects of Inspections and Client Risk on Auditors' Low-Quality Decisions. The model includes a random intercept for each participant to adjust for the correlation of repeated observations for each participant. Panel C presents results of follow-up planned contrasts from the generalized linear mixed-effects logistic regression model. *Onetailed p-value for directional predictions. All other p-values are two-tailed.
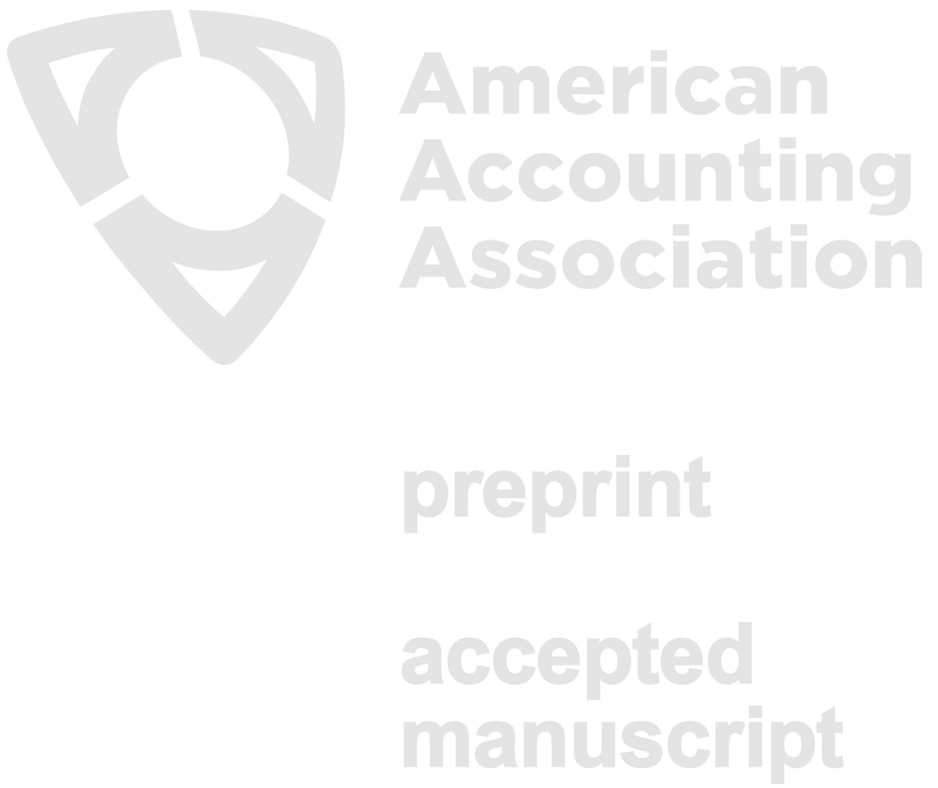


\section{Table 3}

\section{Results of Mediating Process Model Variables}

\begin{tabular}{|c|c|c|c|}
\hline \multirow[b]{2}{*}{$\begin{array}{l}\text { Inspection } \\
\text { Regime } \\
\end{array}$} & \multicolumn{3}{|c|}{ Client Risk } \\
\hline & $\frac{\frac{\text { Lower- }}{\text { Risk }}}{\underline{\text { not }}}$ & $\frac{\text { Higher- }}{\text { Risk }}$ & Average \\
\hline No Inspection & $\begin{array}{c}6.523 \\
(2.630) \\
n=49\end{array}$ & $\begin{array}{c}5.985 \\
(3.191) \\
n=49\end{array}$ & $\begin{array}{c}6.254 \\
(2.921) \\
n=98\end{array}$ \\
\hline Inspection & $\begin{array}{c}6.030 \\
(2.063) \\
n=47\end{array}$ & $\begin{array}{c}7.647 \\
(2.334) \\
n=47\end{array}$ & $\begin{array}{c}6.838 \\
(2.336) \\
n=98\end{array}$ \\
\hline Average & $\begin{array}{c}6.276 \\
(2.399) \\
n=96\end{array}$ & $\begin{array}{c}6.816 \\
(2.862) \\
n=96\end{array}$ & \\
\hline
\end{tabular}

\section{Panel B: Means (Standard Deviation) of Auditors' Task-Related Anxiety \\ Inspection \\ Regime \\ Overall \\ No Inspection \\ (1.243) \\ $n=49$ \\ Inspection \\ (1.231) \\ $n=47$}

Table 3 presents descriptive statistics for the mediation process model measures including the condition means, standard deviations, and number of observations. The independent variables (Inspections and Client Risk) are described in the notes of Figure 1. The means are adjusted for Period and Session. Auditors' Perceived Inspection Risks is a composite measure of the following three questions that elicit participants' perceived importance and pressure for decisions related to lower-risk and higher-risk clients, separately:

(1) "How important was it to you to make accurate reporting decisions for each asset type (Type A and Type B assets)?;” from 0 “Not at all important” to 10 "Extremely Important”,

(2) "To what extent did you feel pressure to choose an effort-level of 3 or more for each asset type (Type A and Type B assets)?;” from 1 "A small extent” to 11 "A great extent," and

(3) "To what extent did you feel pressure to make accurate reporting decisions for each asset type (Type A and Type B assets)?” from 1 "A small extent” to 11 "A great extent."

Auditors' Task-Related Anxiety is measured with the following question: "Please indicate how you felt while making your decisions during the experiment” from 1 "relaxed” to 5 "nervous," (Stone and Kadous 1997). 